\title{
Seasonal contrast in the vertical profiles of aerosol number concentrations and size distributions over India: Implications from RAWEX aircraft campaign
}

\author{
Mukunda M Gogoi ${ }^{1, *}$, N B Lakshmi ${ }^{1}$, Vijayakumar S Nair ${ }^{1}$, \\ Sobhan Kumar Kompaldi ${ }^{1}$, K Krishna Moorthy ${ }^{2}$ and S Suresh Babu ${ }^{1}$ \\ ${ }^{1}$ Space Physics Laboratory, Vikram Sarabhai Space Centre, Thiruvananthapuram 695 022, India. \\ ${ }^{2}$ Centre for Atmospheric and Oceanic Sciences, Indian Institute of Science, Bengaluru 560 012, India. \\ *Corresponding author. e-mail: dr_mukunda@vssc.gov.in
}

MS received 5 June 2018; revised 10 May 2019; accepted 12 June 2019

Aircraft measurements of the vertical profiles of aerosol total number concentrations and size distributions (in the size range of $0.5-20 \mu \mathrm{m}$ ) were made over seven geographically diverse locations of the Indian mainland during two contrasting seasons, winter (December 2012) and spring (April-May 2013), as a part of the regional aerosol warming experiment (RAWEX). Our observations revealed an increase in the vertical extent of aerosol loading during spring having a significant enhancement in coarse mode aerosols in the lower free-troposphere (FT) over western and central parts of India and the Indo-Gangetic plains (IGP). The particulate depolarisation ratio (PDR) derived from the Cloud Aerosol Lidar and Infrared Pathfinder Satellite Observation (CALIPSO) over the same region showed the presence of dust (including polluted dust) at higher altitudes in spring. Concurrent and collocated measurements of aerosol scattering and absorption properties aboard the aircraft revealed that the FT enhancement in coarse mode aerosol loading during spring is associated with a decrease in single scattering albedo and an increase in columnar absorption aerosol optical depth. This confirms that the elevated layers of coarse mode aerosols seen during spring are absorbing in nature, especially over the IGP. The presence of such coarse-mode absorbing aerosols plays a crucial role in governing the radiation balance over the IGP in spring through the diabatic heating of the upper atmosphere.

Keywords. Aerosol number concentration; size distribution; coarse mode fraction; single scattering albedo; CALIPSO; vertical profile.

\section{Introduction}

Atmospheric aerosols, having highly diverse physical and chemical properties, due to their varying production mechanisms and transformation processes, result in complex optical characteristics and radiative interactions (e.g., Prospero et al. 1983; Dubovik et al. 2018). It is of paramount importance to quantify the effects and impacts of these particles on climate, environment and human health. In the context of climate forcing, number size distribution (NSD) is perhaps the most important microphysical property of aerosols, which plays a prominent and dynamic role in radiative interactions (Satheesh et al. 2002; Babu et al. 2006; Moorthy et al. 2007). In 
particular, NSD information is important while determining the spectral variation of aerosol optical properties and has been an important subject of investigation since the 'Junge-period' (e.g., Junge 1963). The knowledge of the aerosol size distribution is also important to understand the evolving processes through the gas phase, vapour phase and particle phase. While understanding the physics and chemistry of ultra-fine mode aerosols is important in studies involving processes such as coagulation, condensation, evaporation, adsorption/desorption, heterogeneous chemistry and nucleation, those in the accumulation regimes assume importance in optical and radiative interactions. Characterisation of coarse-mode aerosols is important to understand the external controlling processes (e.g., convection), as it involves complex particle surface and turbulence-particle interaction, where the morphology of the surface plays an important role. In problems involving radiative interactions, the aerosol size distribution decides the scattering phase function and the angular distribution of scattered intensity. Due to the variety of source processes and the continuous modification by atmospheric processes (coagulation, condensation, cloud cycling, etc.) and meteorology, the size distribution depicts variations temporally, spatially and also vertically.

The above aspects are highly essential to be monitored over the Indo-Gangetic plains (IGP) of India, which is recognised as one of the global hotspots of aerosols. The IGP depicts large variation in aerosol types, resulting from the combined action of synoptic and mesoscale meteorological processes, long-range transport, seasonally competing natural and anthropogenic emissions and the soil type. This is further aided by its peculiar topography, spatially confining and channelling these particles across the IGP until they are flushed out to the northern Bay of Bengal (Nair et al. 2007; Gautam et al. 2010, 2011; Lawrence and Lelieveld 2010; Moorthy et al. 2013). Consequently, aerosols over the IGP are a complex mixture of dust (from the western Indian desert), black carbon (BC), organic carbon (OC) and other anthropogenic species produced locally (including those formed from the gaseous precursors) as well as from nearby and distant sources. Apart from the IGP, studies on aerosol properties over other geographically diversified regions of India have also shown large spatial and temporal heterogeneity, thus making it very challenging to derive an accurate regional scenario of the climate-impact of aerosols.

Characterisation of near-surface aerosol size distributions over the Indian region has been extensively studied using in situ measurements (Pillai and Moorthy 2001 over Trivandrum; Reddy et al. 2007 over Anantapur; Gogoi et al. 2011 over Dibrugarh, etc.). However, one of the most important paucities is the lack of knowledge on the vertical profiles of NSD and their spatiotemporal variations over the Indian mainland. Knowledge of the vertical profiling of the aerosol size distribution over the Indian region is essential to improve the accuracies of radiative forcing estimations based on the quantification of heightresolved aerosol information. However, in situ characterisation of the aerosol size distribution over the Indian region is very limited, even though a few region-specific satellite-based studies (Gogoi et al. 2013) or the inversion of columnar aerosol extinction properties (e.g., Moorthy and Satheesh 2000; Gogoi et al. 2009) have provided information on aerosol types and source characteristics at a few selected locations. For example, over the western part of India, the analysis of vertical profiles of aerosol extinction and volume depolarisation ratio indicated the presence of strong dust layers in the altitude region of $4-6 \mathrm{~km}$, ascertaining the high-aerosol index (Gogoi et al. 2013). As the major desert (Thar) is located between north-western India and central Pakistan, the magnitude of dust impact is especially experienced over semi-arid and arid regions of north-western India. Moorthy et al. (2007) have reported that the absorption efficiency of dust over the Indian region is substantially higher than that over the Saharan regions, probably due to the mixing of dust with other species, or due to the higher hematite content. Climate simulations have shown the possible impacts of elevated absorption and resulted warming on monsoon circulation and rainfall distributions over Asia (Lau et al. 2006; Satheesh et al. 2008; Gogoi et al. 2014). With the above background, we have examined aerosol size distributions over distinct geographical parts of India based on in situ measurements, supplemented by aerosol scattering and absorption measurements, during two aircraft campaigns that were conducted during winter 2012 and spring 2013. The winter phase of the campaign was carried out from 17 November to 30 December 2012, while the pre-monsoon (spring) phase was executed from 25 April to 24 May 2013. 


\section{Aircraft campaign and observational sites}

The aircraft campaign was a part of regional aerosol warming experiment (RAWEX), a project under the Indian Space Research Organisation's Geosphere Biosphere Programme (ISRO-GBP). The airborne measurements of aerosols were carried out to (i) understand the contribution and seasonality of elevated layers of absorbing aerosols (dust and $\mathrm{BC}$ ) in the regional warming and (ii) delineate the share of long-range transport and local contributions to the overall aerosol loading and climatic implications. In this context, flight sorties of a twin-engine turboprop aircraft (Super King Beech craft, B200 of National Remote Sensing Centre, ISRO) were operated over seven distinct locations of central India (CI) and northern India (NI). Figure 1 shows the geographical positions of the base stations, viz., Hyderabad (HYD), Nagpur (NGP), Lucknow (LKN), Dehradun (DDN), Jodhpur (JDR), Jaipur (JPR), Patna (PTN) and Ranchi (RNC), along with the photograph of the aircraft and the inlet system used in the campaign. To understand the seasonal contrasts in aerosol properties, airborne measurements over each of the selected sites (other than PTN) were conducted during two contrasting seasons: winter (December 2012) and spring (April-May 2013). The wintertime measurements at the preselected site PTN were avoided due to foggy and low-visibility conditions, but were carried out at a nearby location, RNC. Thus, the measurements from RNC and PTN are representatives of the aerosol conditions during winter and spring over the eastern part of the IGP.

During the entire campaign, the patterns of aircraft sorties were uniformly maintained at all the locations, each sortie making measurements at six altitude levels, with about $30 \mathrm{~min}$ of sampling time at each level. This was worked out based on the aircraft endurance $(4 \mathrm{~h})$ and the ceiling altitude permissible for unpressurised mode of operation $(\sim 4 \mathrm{~km})$ as described in an earlier paper (Babu et al. 2016). At each altitude, the data collected during the first five minutes of aircraft operation were discarded in the analysis to exclude the effects of any flow instabilities during flight manoeuvering (Babu et al. 2006). As such, the average sampling period in each level varied between 20 and $25 \mathrm{~min}$. All the sorties were made around noontime after the convective boundary layer had fully evolved, so that aerosols were well mixed along the vertical. Occasional cloud-contaminated data encountered during the experiment were screened based on a $2 \sigma$ criterion, in which a sudden increase in aerosol number concentrations at a particular level lying outside $2 \sigma$ of the level average values was examined and all aerosol data for that period collocated were discarded from further analysis. Overall, the percentage of discarded cloud contaminated data is $<3 \%$.

During the experiment, the isokinetic flow of the inlet sample was attained by maintaining (by an external pump) a volumetric flow rate of $\sim 70 \mathrm{LPM}$ (based on laboratory calculations for an average speed of $300 \mathrm{~km} / \mathrm{h}$ for the aircraft during sampling)

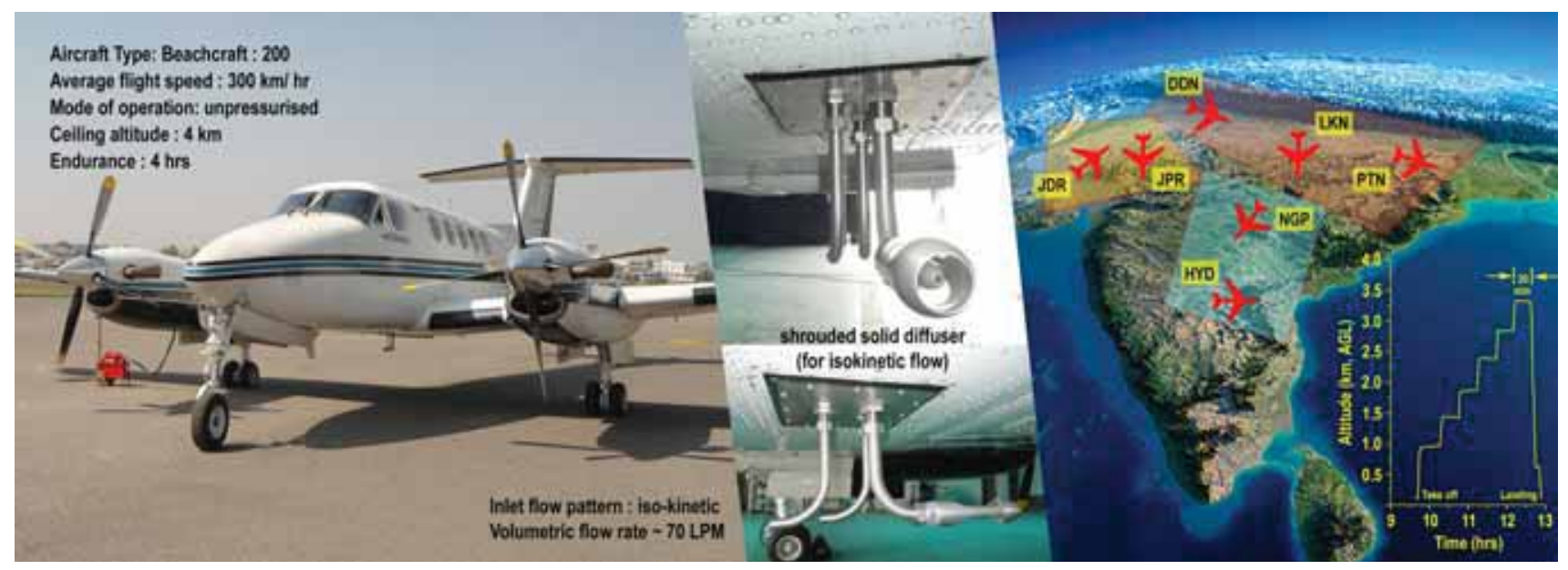

Figure 1. The Indian Space Research Organisation (ISRO) aircraft (left) used in the present study, along the shrouded solid diffuser inlet (middle) and the measurement locations (right) of RAWEX during winter 2012 and pre-monsoon 2013. The shaded areas represent the broad regional classification (HF, WI, IGP and CI) of these stations. Typical staircase profiling at different altitudes are also shown. 
to sample the air containing aerosols through a shrouded solid diffuser (University of Hawaii) for near-isokinetic sampling. The effectiveness of such a diffuser inlet for sampling of aerosols in the submicron size without a significant particle loss has been reported (Huebert et al. 2004; Mc Naughton et al. 2007). More details are available in Babu et al. (2016). To exclude the aircraft emission in the measurements, the front facing isokenetic inlet was mounted close to the front side of the aircraft and at a position much ahead of the exhaust area of the engines. Thus, the exhausts of the engines were passing much away from the sampling inlet.

Following the above-mentioned protocol, aircraft measurements were carried out from the selected base stations (details are given in table 1). Broadly, these locations were selected to represent the urban/anthropogenic sources and types of aerosols over CI and NI and urban/arid sources and types of aerosols over western India (WI). Based on this classification, LKN, PTN/RNC and $\mathrm{DDN}$ are located in the northern part of India, more precisely LKN in the central and PTN/ RNC in the eastern parts of the IGP, while DDN is a Himalayan foothill (HF) site. JDR and JPR are located in the arid/semi-arid regions of $\mathrm{WI}$, while HYD and NGP are located almost at the geographical centre of India.

Interestingly, all of the above sites are representative of urban centres (dominated by anthropogenic emissions from industry, homes and traffic), as can be classified based on the criterion of population density. According to this, all places which possess a minimum population of 5000 (a density of population of at least 400 per sq. km.) and at least $75 \%$ of the male main workers engaged in non-agricultural pursuits are categorised as the urban area (Census of India 2011). Babu et al. (2013) have also used the population criterion to classify the distinct geographic regions of India (urban: population $>2$ million; semi-urban: 2 million $>$ population $>0.5$ million; rural: population $<0.5$ million). Depending on their geographical positions, the types of aerosols occurring over these sites vary with seasons. Babu et al. (2016) and Nair et al. (2016) have reported regional distinctiveness of the vertical profiles of aerosol optical properties over the same geographic locations considered in the present study, based on the data collected from the same airborne experiment. In their studies, the seven base stations were considered to represent distinct aerosol environments over the central, western, IGP and HF locations of India.

Located in the middle of the IGP, LKN $\left(26.76^{\circ} \mathrm{N} ; 80.88^{\circ} \mathrm{E}, 123 \mathrm{~m}\right.$ a.s.l. $)$ is among the most polluted cities in the world by particulate matter concentration (WHO Global Ambient Air Quality Database), with a major share coming from vehicular traffic (Barman et al. 2017). As per the 2011 census, LKN has a population of 8.82 million. Similarly PTN $\left(25.59^{\circ} \mathrm{N}\right.$; $85.09^{\circ} \mathrm{E}, 54.5 \mathrm{~m}$ a.s.l. $)$, located on the southern bank of the river Ganges towards the eastern part of India, is also in the list of highly polluted environment (population -1.07 million), which also experience heavy fog conditions during winter. DDN $\left(30.19^{\circ} \mathrm{N} ; 78.18^{\circ} \mathrm{E}\right.$, $670 \mathrm{~m}$ a.s.l.), located in a valley in the Shiwalik range in the foothills of the Himalayas, experiences a significant influence of the IGP from the south and east of it. To the north and east, DDN is under the influence of high altitude Himalayas (the Himalayan mountain ranges, more than $\sim 2000 \mathrm{~m}$ tall, are located $\sim 300 \mathrm{~km}$ away from this site). The population at DDN is 0.58 million (2011 census).

In the western part of India, JDR $\left(26.25^{\circ} \mathrm{N}\right.$; $73.05^{\circ} \mathrm{E}, 426 \mathrm{~m}$ a.s.l.) is adjacent to the Thar desert, while JPR $\left(26.83^{\circ} \mathrm{N} ; 75.82^{\circ} \mathrm{E}, 431 \mathrm{~m}\right.$ a.s.l. $)$ is an urban area located north-west of JDR. The Aravalli hills (mean elevation of 500-600 m), lying a few hundred kilometres to the east of JDR, act as a barrier separating it from the eastern plains of

Table 1. Operation details of aircraft at different locations of India during the winter and spring phase of RAWEX.

\begin{tabular}{|c|c|c|c|c|c|}
\hline & & Winter (November-December) & & Spring (Apr-May) & \\
\hline Region & Location & 2012 & Time & 2013 & Time \\
\hline \multirow[t]{2}{*}{ CI } & Hyderabad (HYD) & 18/19 November & $10: 30-15: 30$ & 25/26/27 April & $11: 30-14: 30$ \\
\hline & Nagpur (NGP) & 3/4/5 December & $10: 30-14: 00$ & 1/2 May & 09:30-13:30 \\
\hline \multirow[t]{2}{*}{ IGP } & Lucknow (LKN) & 8/9/10 December & 11:00-14:30 & 5/6/7 May & 09:30-13:00 \\
\hline & Patna (PTN)/Ranchi (RNC) & 27/28/29 December & 11:00-14:00 & 9/10/12 May & $10: 00-13: 30$ \\
\hline $\mathrm{HF}$ & Dehradun (DDN) & 12/13/15 December & $10: 30-15: 00$ & 14/15/16 May & 10:00-14:00 \\
\hline \multirow[t]{2}{*}{ WI } & Jodhpur (JDR) & 17/18/19 December & $10: 30-14: 30$ & 18/20 May & 09:30-13:00 \\
\hline & Jaipur (JPR) & 22/24 December & $11: 00-14: 30$ & 22/23/24 May & $10: 00-14: 00$ \\
\hline
\end{tabular}


India (Moorthy et al. 2007). Strong dust-raising winds occurring from April to July and scanty rainfall ( $<300 \mathrm{~mm}$ annually) influence the aerosol loading over this region. JDR has a population of 1.03 million, nearly $1 / 3$ of that of JPR (population 3.07 million).

In the central part of India, NGP $\left(21.15^{\circ} \mathrm{N}\right.$; $79.15^{\circ} \mathrm{E}, 300 \mathrm{~m}$ a.s.l.) is located far from either the eastern or the western peninsula of India. It has a tropical climate, with dry conditions prevailing throughout the year. It has a population of 2.4 million (Census of India 2011). The region records high temperatures, going up to $48^{\circ} \mathrm{C}$, in the spring season (March to May) (Kompalli et al. 2014). Towards the south-west of NGP, HYD $\left(17.39^{\circ} \mathrm{N} ; 78.49^{\circ} \mathrm{E}, 557 \mathrm{~m}\right.$ a.s.l.) is located in the northern part of the peninsular region. It is a metropolitan city with a population of 6.81 million (Census of India 2011) and has large urban emissions from industries and automobiles (Kompalli et al. 2014).

\section{Measurements, data and analysis}

The present study addresses the seasonality of the vertical profiles of the aerosol size distribution and total number concentrations over seven selected sites in India during winter and spring seasons.

\subsection{Aerosol number size distribution and optical properties}

Near real-time measurements of aerosol NSDs and total number concentrations were made onboard the aircraft using an aerodynamic particle sizer (APS) spectrometer (TSI, Model: 3321) in the size (aerodynamic) range from 0.5 to $20 \mu \mathrm{m}$ (52 channels). The size distribution in APS is determined based on the time of flight of individual particles flowing through an accelerating field. As the measurements are based on the aerodynamic diameter, they are insensitive to the physical size, shape, density and composition of the particles.

During the present study, aerosol samples were drawn into the APS using the isokinetic inlet system described earlier. From the main inlet assembly, the APS aspirated the aerosol samples at a flow rate of $1.0 \pm 0.2 \mathrm{LPM}$, while the sheath flow was maintained at $4.0 \pm 0.1 \mathrm{LPM}$, for a total flow rate of $5.0 \pm 0.1 \mathrm{LPM}$. Any changes in flow rates due to variation in ambient pressure (varying between 1034 and $600 \mathrm{hPa}$ ) during vertical profiling were automatically corrected by the instrument. The effects of change in temperature and relative humidity were small and within the operational ranges of the instrument (between 10 and $45^{\circ} \mathrm{C}$ for temperature and in the $\mathrm{RH}$ range of 10-90\%, non-condensing). Under standard conditions of atmospheric temperature and pressure, the uncertainty of the instrument for coincident measurements is $<2 \%$ (for 1000 particles $/ \mathrm{cm}^{3}$ at $0.5 \mu \mathrm{m}$ diameter) and less than $6 \%$ coincidence (for 1000 particles $/ \mathrm{cm}^{3}$ at $10.0 \mu \mathrm{m}$ diameter). Volckens and Peters (2005) have reported the counting efficiencies of different versions of APS, for a range of particles $(0.8-10 \mu \mathrm{m})$ having different physical (solid or liquid) properties. The liquid aerosols considered in their experiments were monodisperse-liquid droplets, created using serial dilutions of an ethanol-based solution containing oleic acid tagged with uranine (90:10 mixture) and aerosolised with a vibrating orifice generator (VOAG 3450 TSI Inc., Shoreview, MN). On the other hand, monodisperse-solid aerosols include: (i) fluorescent, polystyrene latex (PSL) spheres (Duke Scientific, Palo Alto, CA) nebulised from suspension in distilled, deionised water and (ii) ammonium fluorescent particles created with the VOAG (Vanderpool and Rubow 1988). For solid particles, Volckens and Peters (2005) have reported quite-high counting efficiencies (85-99\%); even though it declined for liquid droplets (from 75 to $25 \%$ corresponding to an increase in the drop size from 0.8 to $10 \mu \mathrm{m}$ drop). Thus, the uncertainty involved with the APS measurements is mainly with aerosols in the liquid phase. As the present study was conducted under dry atmospheric conditions, the uncertainty due to liquid aerosol is minimum. Moreover, the data collected during the passing of the aircraft through occasional clouds in its flight path were discarded. This ensures that the quality of data used in the study is of good confidence level. Other loss mechanisms include the particle losses due to aspiration, transmission, detector error and experimental error. In general, instruments are calibrated prior to the experiment following the standard protocol. To ensure the stability and quality data collection, a factory calibrated freshly procured instrument was employed during the campaign. In addition, the consistency in the APS flow was periodically checked and optical components and tubing of the system were carefully cleaned immediately after moving to a new station. It should also be noted that there is no absolute calibration standard for particle number concentration. The sizing and counting efficiency is checked using Polystyrene latex (PSL) spheres and a reference counter. Along 
with APS, a suite of other instruments was operated in the aircraft. These instruments were also precalibrated prior to the experiment. The details of calibration, the associated uncertainties and the mode of operation of various instruments in the same airborne platform were reported by Babu et al. (2016) and Nair et al. (2016). To ensure the normal operating condition in the aircraft, the isokinetic flow was ensured during the motion of the aircraft and thus the stability of the measurements.

\subsection{Data processing}

The particle concentration $\left(n_{i}\right)$ in the $i^{\text {th }}$ channel of the APS is estimated based on the particle counts per channel $\left(c_{i}\right)$, sampling time $(t)$, sampling flow rate $(Q)$, sample dilution $\left(\varphi_{i}\right)$ and sample efficiency factor per channel $\left(\eta_{i}\right)$, which gives the number of weighted concentration per channel as

$$
n_{i}=\frac{c}{t Q} \frac{\varphi_{i}}{\eta_{i}} .
$$

The total concentration $(N)$ for each sample is then

$$
N=\sum_{l}^{u} n_{i}
$$

where $l$ and $u$ represent the lower and upper boundary of the APS channels. The other parameters of interest, such as the geometric mean diameter $\left(D_{\mathrm{g}}\right)$ and geometric standard deviations $\left(\sigma_{\mathrm{g}}\right)$ are calculated as

$$
\begin{gathered}
D_{\mathrm{g}}=\exp \left[\frac{\sum_{l}^{u} n \ln \left(D_{\mathrm{pi}}\right)}{N}\right] \\
\sigma_{\mathrm{g}}=\exp \left[\frac{\sum_{l}^{u} n\left[\ln D_{\mathrm{p}}-\ln D_{\mathrm{g}}\right]^{2}}{N}\right]^{1 / 2} .
\end{gathered}
$$

Here, $D_{\mathrm{p}}$ denotes the midpoint diameter of each channel.

Concurrent measurements of scattering $\left(\sigma_{\text {sca }}\right)$ and absorption $\left(\sigma_{\text {abs }}\right)$ coefficients were also made onboard using a three-channel (450, 550 and 700) integrating nephelometer (TSI 3563, USA) and a seven channel $(370,470,520,590,660,880$ and $950 \mathrm{~nm}$ ) aethalometer (Model-AE33, Magee scientific, USA), respectively. The details of the deployment and operation protocol onboard, measurements and data analysis methodologies were discussed in earlier studies (Babu et al. 2016; Nair et al. 2016) and are not repeated here. The nephelometer was calibrated prior to the aircraft experiment, using carbon dioxide as high-span gas and air as low-span and again after the campaign to ensure the stability of the system.

The pressure and flow-integrity issues of the nephelometer operation onboard the aircraft were less significant in this experiment as the measurements were carried out under unpressurised conditions (ambient and cabin pressure remained the same) and the ceiling altitude never exceeded $650 \mathrm{hPa}$ (corresponding to $3-3.5 \mathrm{~km}$ a.s.l.). Thus the leak and pressure integrity issues were only of secondary nature. In the case of the aethalometer, the steady sample flow was ensured by frequently monitoring the total flow and sample flow rates externally. In addition, as it is very difficult to maintain a constant flow during take-off, landing, ascending and descending from one level to another, the first $5 \mathrm{~min}$ data after attaining each level were excluded from further analysis.

The inherent biases of the nephelometer (angular truncation) and the aethalometer (multiple scattering and loading effects) measurements were rectified following the correction schemes proposed by Anderson and Ogren (1998) and Arnott et al. (2005), respectively, and described in the earlier studies (Babu et al. 2016; Nair et al. 2016). The corrected values of scattering and absorption coefficients were used for the estimation of singlescattering albedo (SSA), as well as extracting information on distinct aerosol/source types based on their wavelength dependence, inferred by linear least squares fit to the relation,

$$
\sigma_{\mathrm{sca}, \mathrm{abs}}=\beta \lambda^{-\alpha_{\mathrm{sca}, \mathrm{abs}}}
$$

where $\sigma_{\text {sca }}$ and $\sigma_{\text {abs }}$ are scattering and absorption coefficients and $\alpha_{\text {sca }}$ and $\alpha_{\text {abs }}$ are wavelength exponents for scattering and absorption, respectively. Using the wavelength dependence of $\sigma_{\text {sca }}$, the nephelometer values were extra/interpolated to the aethalometer wavelengths to estimate SSA at common wavelengths.

\section{Results and discussion}

\subsection{Vertical profiles of aerosol total number concentrations and size distributions}

The regional and seasonal distinctiveness of the vertical profiles of aerosol total number concentrations $\left(N_{\mathrm{T}}, \mathrm{cm}^{-3}\right)$ over the distinct regions of $\mathrm{HF}$, 
WI, IGP and CI are depicted in figure 2; denoted by blue and red symbols to the values for winter and spring seasons, respectively. The starting points of all profiles represent the surface altitude (in ' $\mathrm{m}$ ') of individual base-stations above the mean sea level (a.s.l.).

The figure indicates higher values of $N_{\mathrm{T}}$ near the surface at all observational sites during both winter and spring, having higher values in winter than in spring. This indicates the confinement of aerosols (local emissions) within the shallow atmospheric boundary layer (ABL) during the winter season. During spring, increased vertical mixing due to higher-thermal convection resulted in the dilution of the near-surface concentration.

The highest near-surface aerosol concentration was seen at LKN in the IGP, which varied between $342.2 \pm 17.2$ and $528.4 \pm 12.4 \mathrm{~cm}^{-3}$, while the $\mathrm{HF}$ site DDN showed the lowest concentrations $\left(22.4 \pm 3.1\right.$ to $54.8 \pm 3.6 \mathrm{~cm}^{-3}$, an order of magnitude lower than the highest concentrations at LKN) during the winter phase of the experiment. Vertically, aerosol concentrations decreased, in general, with an increase in altitudes during both the seasons; however, there were certain region-specific features. Over LKN and DDN, $N_{\mathrm{T}}$ appears to depict larger variation at the higher altitudes (above $\sim 1.5$ to $2 \mathrm{~km}$ ) above the local boundary layer in winter. By higher altitude, we refer to the lower free-tropospheric (FT) regions above the well-mixed ABL.

In contrast to winter, $N_{\mathrm{T}}$ showed enhanced vertical homogeneity during spring at all observational sites; attributed to the enhanced vertical mixing during this season caused by the thermal convection. In summary,

1. Near-surface (at lower atmospheric altitudes below $\sim 1 \mathrm{~km}$ ) aerosol concentrations were higher during winter than in spring.

2. In the lower FT (above $\sim 2 \mathrm{~km}$ ), the number concentrations tend to be higher in spring than in winter. More homogeneous distribution of the particles in spring leads to the increased aerosol concentrations at higher altitudes.

3. The spatial pattern of near-surface aerosol concentration in winter showed the highest abundance over the industrialised location LKN $\left(N_{\mathrm{T}}>100 \mathrm{~cm}^{-3}\right)$ in the IGP, while the

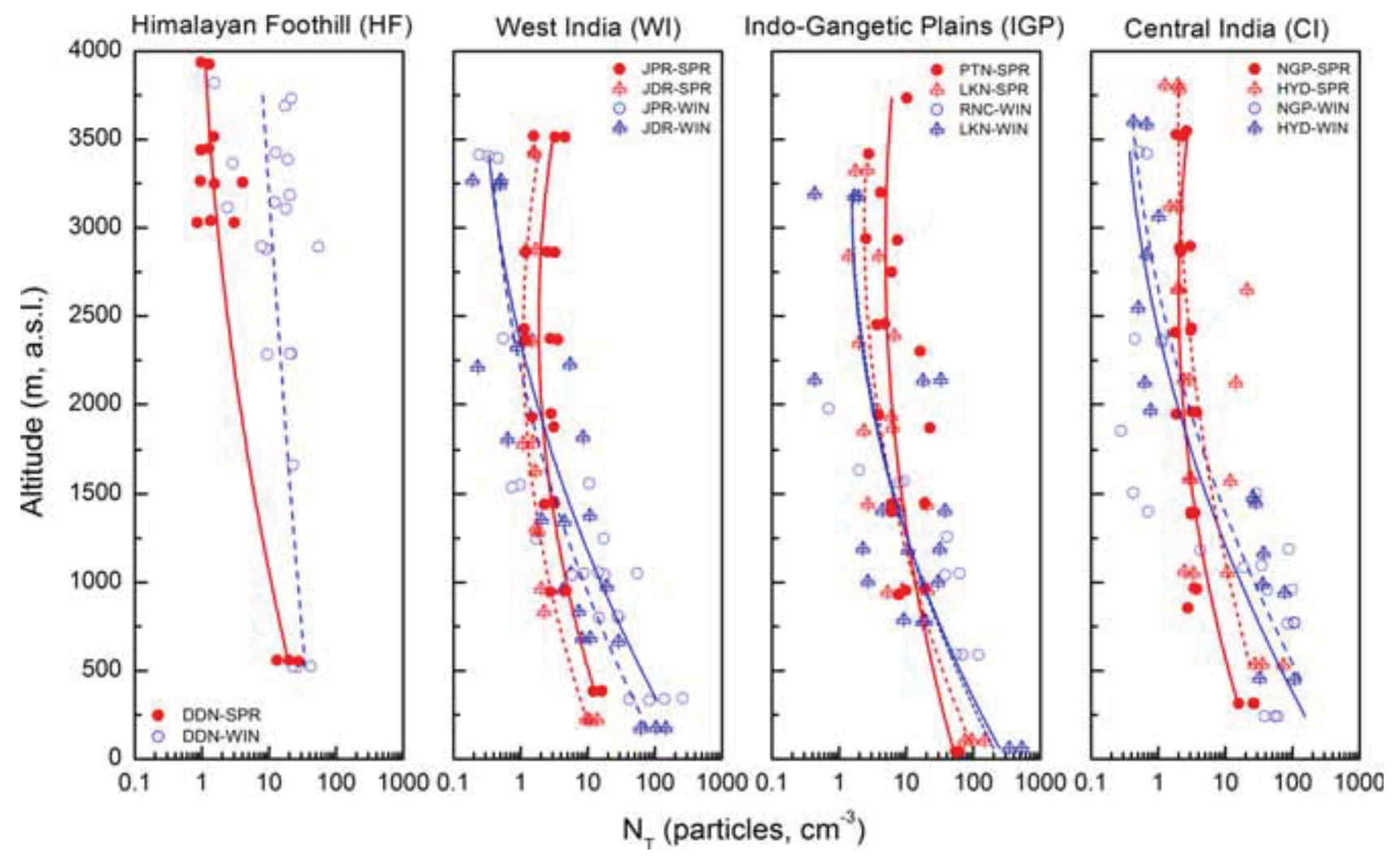

Figure 2. Vertical profiles of total number concentration $\left(N_{\mathrm{T}}\right)$ of aerosols. The red lines joining the red symbols represent spring season and blue lines joining the blue symbols represent the winter season. The fitted lines with respect to the solid and open circles are shown by the solid lines, while those fitted for the asterisk symbols are shown by the dashed lines. A.S.L. stands for altitude above sea level. The starting points of all the profiles in each panel correspond to the station heights above mean sea level. 
lowest concentrations (lower by an order of magnitude) were seen at the HF site DDN $\left(N_{\mathrm{T}}\right.$ $\sim 20 \mathrm{~cm}^{-3}$ ).

4. Spring time enhancement in aerosol total number concentrations in the lower-FT altitude (beyond $2 \mathrm{~km}$ ) is more significant over the central (HYD, NGP) and the west (JDR and JPR) Indian locations. While LKN in IGP showed a mixed pattern with the enhancement occurring only at altitudes $\sim 2 \mathrm{~km}$ or above, DDN depicted higher values in winter even up to an altitude of $3.5 \mathrm{~km}$.

In view of the above, the average values of $N_{\mathrm{T}}$ at each of the locations were examined separately for two vertical regimes; one within the ABL (below $1 \mathrm{~km}$ ) and the other in the FT region (above $2 \mathrm{~km}$ ). It may be noted that this classification may not hold good in completeness during spring over some of the locations like NGP, where ABL heights extend to more than $2 \mathrm{~km}$ (Kompalli et al. 2014). Nevertheless, such classification helps in delineating near-surface and elevated-aerosol contribution. The mean values of $N_{\mathrm{T}}$ during winter and spring, along with the variability of $N_{\mathrm{T}}$ from winter to spring for the FT (given as $N_{\mathrm{T}}$ ratio $=\left(N_{\mathrm{T}}\right.$, SPR $\left.\left.-N_{\mathrm{T}, \text { wIN }}\right) / N_{\mathrm{T}, \mathrm{SPR}}\right)$ ) and within the ABL (given as $N_{\mathrm{T}}$ ratio $=\left(N_{\mathrm{T}}\right.$, SPR $-N_{\mathrm{T}}$, wIN $) / N_{\mathrm{T}}$, wiN $\left.)\right)$, are shown in figure 3 . The figure clearly shows that the average values of $N_{\mathrm{T}}$ in the well-mixed region (below $1 \mathrm{~km}$ ) in winter is higher $\left[N_{\mathrm{T}}\right.$-ratio, goes as high as 80\%] at all locations. However, over the
lower-FT region (above $2 \mathrm{~km}$ ), enhancement in the aerosol concentrations during spring $(>50 \%)$ is clearly seen over the IGP, WI and CI regions (highest enhancement ( $\sim 86 \%)$ of aerosol concentration was seen at HYD). On the other hand, the winter to spring ratio of the average values of $N_{\mathrm{T}}$ (above $2 \mathrm{~km}$ ) at the HF site DDN showed an opposite pattern, depicting significant reduction of $N_{\mathrm{T}}$ from winter to spring. This feature is unique occurring over the northern part of India; possible reasons for which are examined in the subsequent sections.

To understand the dominant particle sizes and corresponding modes, mean aerosol NSDs at various altitude regimes (near surface, well-mixed region, transition regions and the lower FT) are examined in figure 4, representative of winter (WIN) and spring (SPR) for the distinct regions. In general, aerosol NSDs, both in the mixed layer and FT regions, found to follow unimodal distributions (within the size range of $0.5-20 \mu \mathrm{m}$ ). The distributions also showed variations in particle concentrations at different size bins corresponding to the measurements in different altitude regions as well as during winter and spring. Near the surface, seasonal changes in aerosol-size distributions (primary mode occurring at $\sim 0.8 \mu \mathrm{m}$ for the size range of aerosols considered in the present study) were more conspicuous at JDR and JPR in the western part of the country having higher concentrations of the fine mode particle in winter. On the other hand,

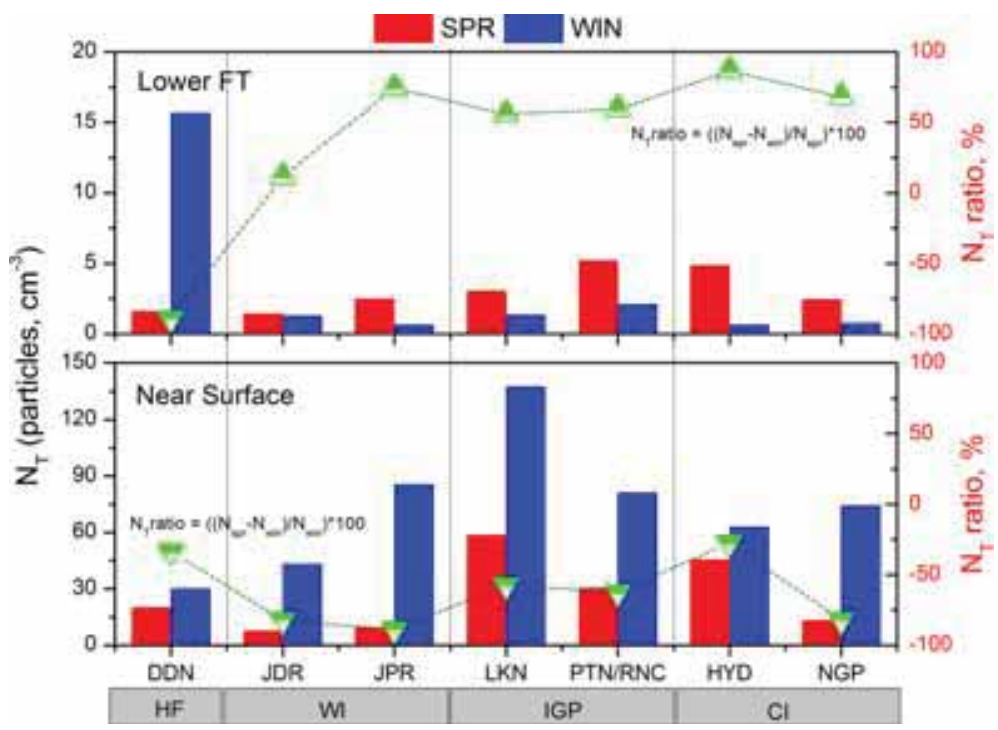

Figure 3. Aerosol total number concentrations $\left(N_{\mathrm{T}}, \mathrm{cm}^{-3}\right)$ in the well-mixed layer and lower FT during spring (SPR) and winter (WIN), along with the variability of $N_{\mathrm{T}}$, (normalised difference) from winter to spring within the ABL (given as $N_{\mathrm{T}}$ ratio $\left.=\left(N_{\mathrm{T}, \mathrm{SPR}}-N_{\mathrm{T}, \mathrm{wIN}}\right) / N_{\mathrm{T}, \mathrm{wIN}}\right)$ and in the lower-FT (given as $N_{\mathrm{T}}$ ratio $\left.=\left(N_{\mathrm{T}, \mathrm{SPR}}-N_{\mathrm{T}, \text { wIN }}\right) / N_{\mathrm{T}, \mathrm{SPR}}\right)$ over selected locations of India. 


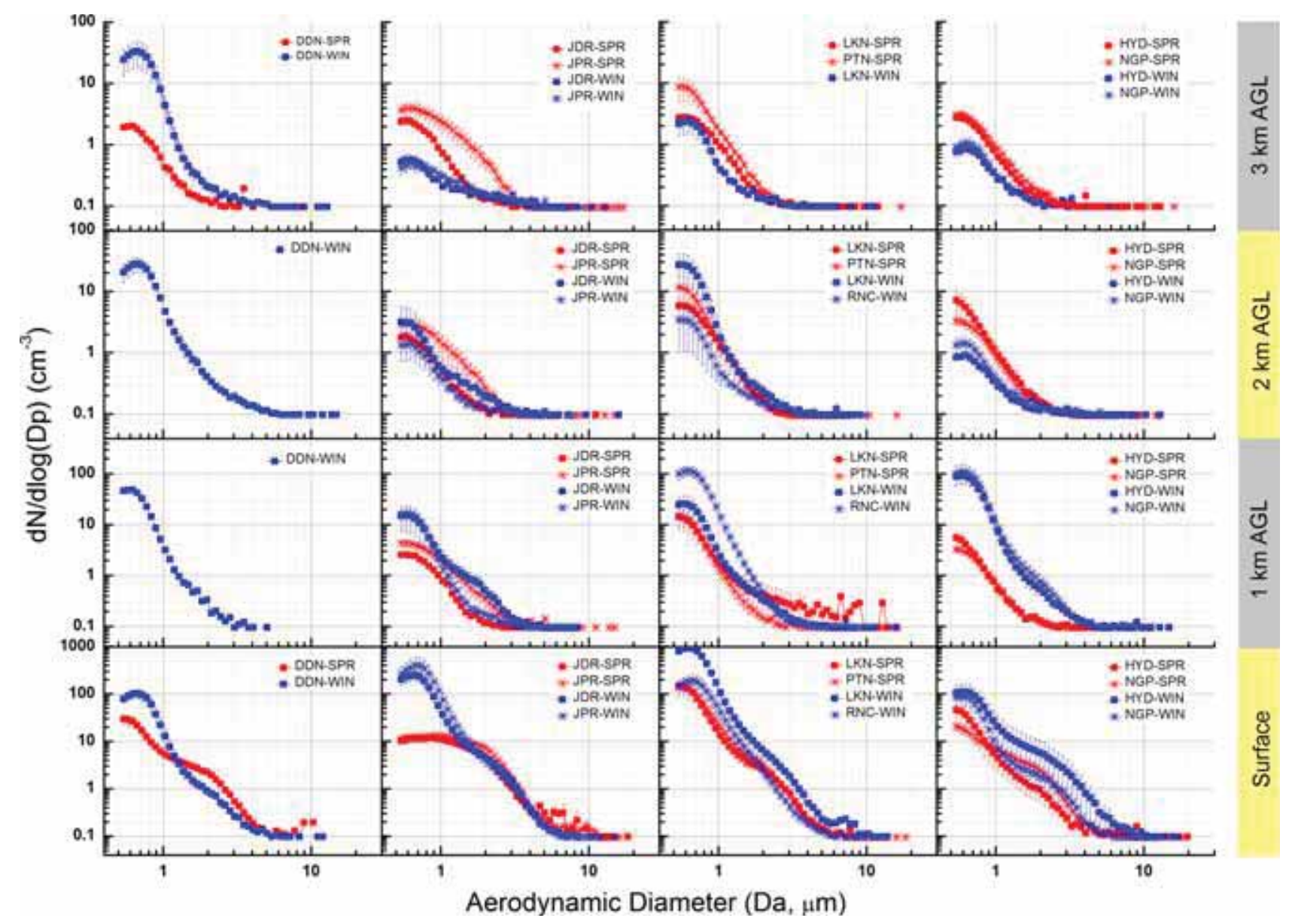

Figure 4. NSDs $\left(\mathrm{d} N / \mathrm{d} \log \mathrm{Dp}, \mathrm{cm}^{-3}\right)$ at four distinct altitude regimes (surface, 1,2 and $3.5 \mathrm{~km}$ AGL) during spring (SPR, red colour) and winter (WIN, blue colour) over the HF: DDN; WI: JDR and JPR, IGP: LKN, RNC/PTN and CI: HYD and NGP). AGL stands for altitude above ground level.

near-surface aerosol size distributions across the entire size range were higher over the IGP and CI in winter. The seasonal distributions over these locations gradually coincide at 1 and $2 \mathrm{~km}$ altitudes. At higher altitudes beyond $2 \mathrm{~km}$, size distributions in spring dominate the entire size spectra at all locations except DDN. At the HF site DDN, the aerosol-size distribution in winter was significantly higher even at the FT altitude, while the measurements at WI and IGP locations showed more conspicuous enhancements in the FT regions, with a corresponding decrease at the surface.

\subsection{Parameters of aerosol NSDs}

To quantify the seasonal variations of the altitudinal distributions of aerosol NSDs, various parameters, such as mode $\left[D_{\mathrm{p}}\left(n_{\max }\right)\right]$, geometric mean diameter $\left(D_{\mathrm{g}}\right)$ and coarse mode $(>1 \mu \mathrm{m})$ number concentrations $\left(N_{\mathrm{C}}\right)$ of aerosols were examined. Values of $N_{\mathrm{C}}$ were estimated to quantify the influence of coarse mode aerosols (which are more likely to be mechanically generated and hence natural), considering $1 \mu \mathrm{m}$ as the cut-off particle diameter from accumulation to coarse (Mönkkönen et al. 2005; Babu et al. 2016), in the size spectra. Vertical profiles of mode and $D_{\mathrm{g}}$ are shown in figure 5 , with the solid and open circles representing the values for spring and winter, respectively. While mode gives the information about the dominant particle size, the geometric mean diameter of a system of particles represents the $50 \%$ probability point of an equivalent diameter having half of the particle concentrations larger than this size and the remaining half below that. As such, a proportionate change in the aerosol number concentrations in the entire size range of a distribution can reveal similar values of $D_{\mathrm{g}}$; however, their optical influence will be different based on their total concentrations at different size regimes. 

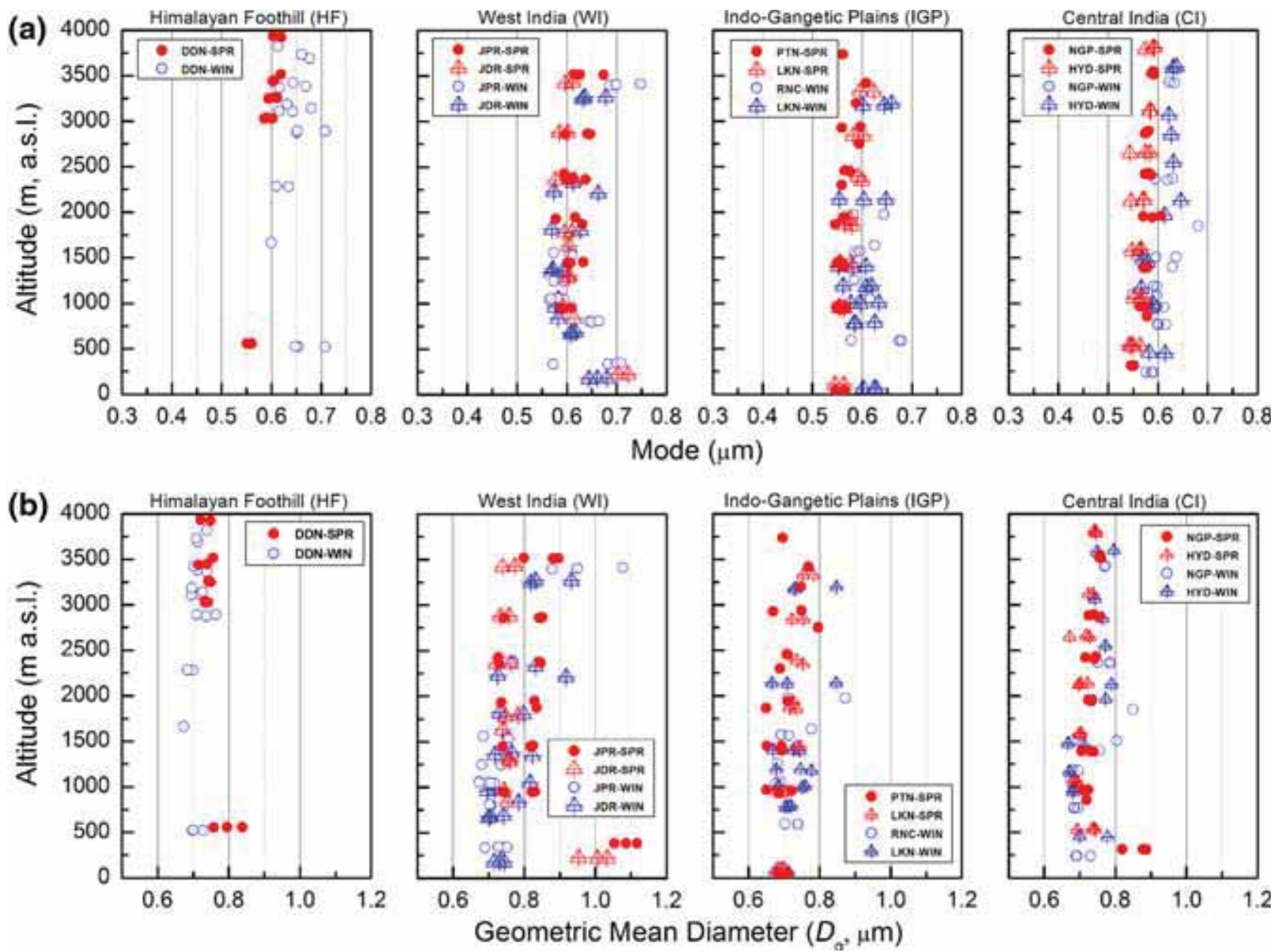

Figure 5. Vertical profiles of modes of the distributions and geometric mean diameters $\left(D_{\mathrm{g}}, \mu \mathrm{m}\right)$ of aerosols in distinct geographic regions of India.

In the present study, the modes of the entire size distributions varied between 0.6 and $0.7 \mu \mathrm{m}$, in general, even though the values of $D_{\mathrm{g}}$ varied over a broad range between 0.7 and $1.1 \mu \mathrm{m}$. As $D_{\mathrm{g}}$ is the number weighted diameter, it is hard to infer a clear picture of the average particle size from the ensemble of particle sizes measured during the present study, as the lower size range of APS is limited to $0.542 \mu \mathrm{m}$.

Figure 6 shows the vertical profiles of coarse mode (number) fraction (CMF $\sim N_{\mathrm{C}} / N_{\mathrm{T}}, N_{\mathrm{T}}$ being the total number of concentrations of aerosols in the size regime captured by APS measurements). It clearly reveals higher values of $\mathrm{CMF}$ above the mixing region in spring over the WI, IGP and HF locations, while the dominance of coarse mode aerosols remained dominant in winter up to lower FT over the CI. The enhancement in CMF at the higher altitudes in spring is the highest over WI ( $>10 \%$ in some days), followed by the IGP. In contrast to this, in the well-mixed region, values of
CMF showed mixed behaviour, showing significant higher values $(>20 \%)$ during spring at WI. The pattern is opposite over the IGP where the dominance of fine mode aerosols is significant near the surface (as indicated by the lower values of CMF) during spring compared to those during winter. On the other hand, the presence of coarse-mode aerosols at higher altitudes (i.e., above the well-mixed boundary layer region) in spring is very interesting and an important aspect in the context of understanding the regional circulation systems as well as their perturbations to the radiative forcing mechanisms.

There are several factors (e.g., turbulent mixing) which influence the vertical dispersion of aerosols from surface to higher altitudes. Inside the ABL, particles are well-mixed due to eddy turbulences associated with solar heating. As the aircraft measurements were obtained during daytime, vertical dispersion is stronger in spring than in winter due to prevailing higher temperatures. This results 


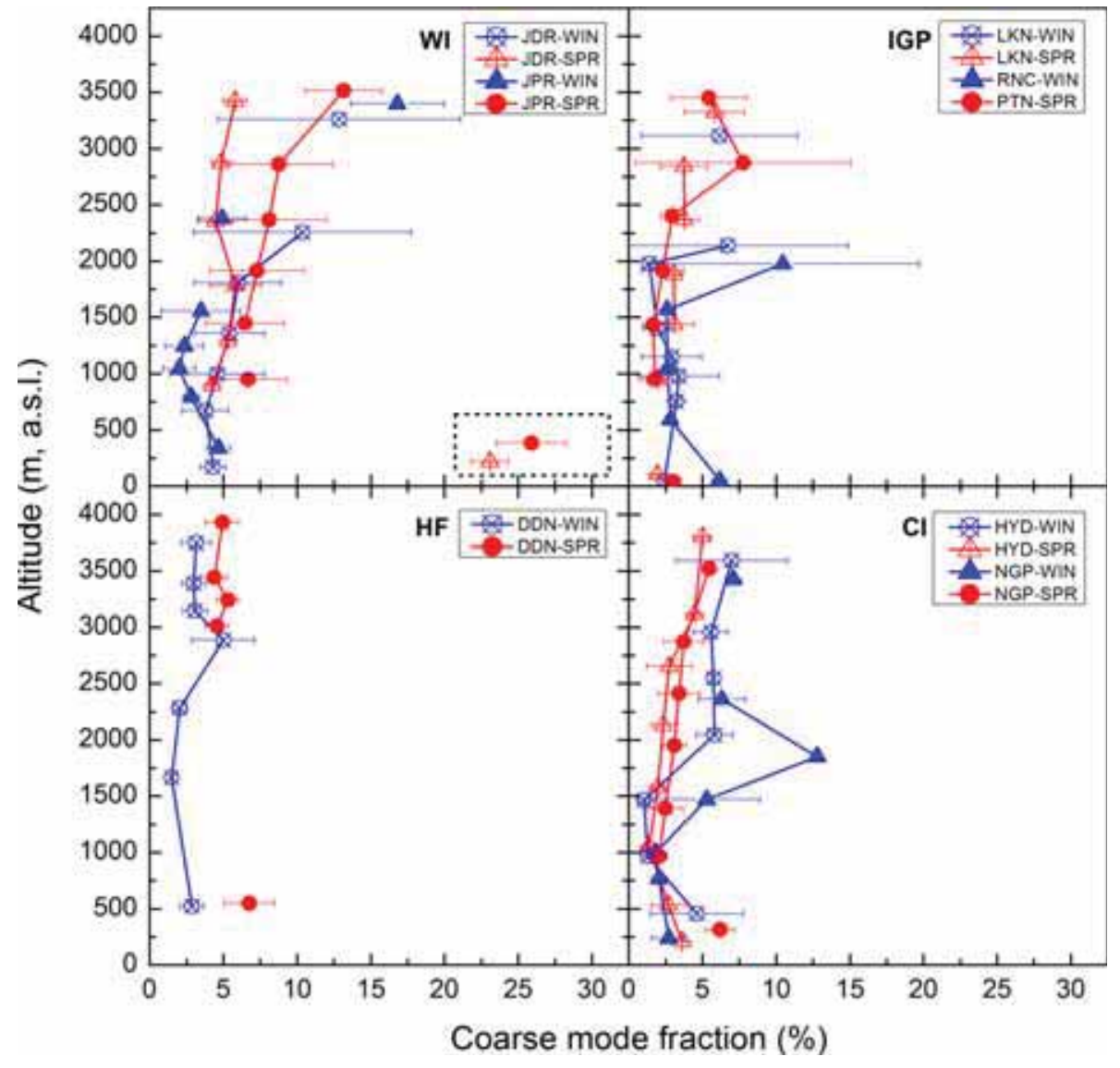

Figure 6. Vertical profiles of aerosol CMF over the regions of WI, IGP, CI and HF.

in increased abundance of aerosol concentrations at higher altitudes during spring compared to winter. In winter, the combined effect of prevailing lower temperatures, calmer wind conditions and decreased solar heating result in weaker convective processes, leading to lower-ABL heights, low-level inversions and a decrease in ventilation of aerosols. Hence, the particles are confined closer to the surface, leading to enhancement in particle concentrations in winter.

Several earlier investigators have reported the abundance and role of coarse-mode aerosols on radiative implications over the Indian region (e.g., Verma et al. 2012). However, most of the observations are based on the near surface in-situ measurements. In contrast, the spatio-temporal variation in the vertical profiles of aerosol size distributions and CMF in the present study assumes the importance to understand the column-integrated properties of aerosols and hints to the upper-level transport of dust from the western part of India to the IGP. During spring, strong vertical mixing raises the coarse particles to higher heights, the long-range transport from the dust-dominated regions of WI may contribute to the enhancement of coarse particle concentrations over the IGP at different altitudes, depending on the wind characteristics. During May, the thermal or heat low (i.e., nonfrontal low pressure area occurring over the arid regions due to intense heating) leads to build up of a temperature gradient at lower atmospheric levels. The heated air in the lowermost layer of the atmosphere expands in volume, becomes light and rises higher in the atmosphere, thus intensifying the largescale convective processes. Thus, the air masses passing through this region are transport pathways for dust due to the presence of the Thar desert. Apart from the Thar as the primary source of dust loading in north-western India, dust transport from the Arabian Peninsula and the Middle East Gulf regions are important during the spring season. Several earlier investigators have reported the advection of mineral dust from West Asia or the Thar to the north Indian region during the premonsoon season and their radiative consequences have been discussed (Moorthy et al. 2007; Beegum et al. 2009).

As far as dust influence is concerned, mineral dust particles are not spherical. The pure mineral dust, which is absorbed in UV and visible 
wavelengths because of the hematite content $\left(\mathrm{Fe}_{2} \mathrm{O}\right)$ present in the dust, interacts with carbonaceous species like $\mathrm{BC}$ and $\mathrm{OC}$ during its transport. This gives rise to complex agglomerates which can be stated as polluted dust (Lelieveld et al. 2002; Sullivan and Prather 2007; Yang et al. 2009a, b). The composite mixture of pure mineral dust with carbonaceous pollutants differs from pure mineral dust in terms of particle morphology, chemical composition (governing refractive index), hygroscopicity and cloud condensation nuclei (Mishra and Shibata 2012a, b). These characteristics of polluted mineral dust govern the deviation in optical properties and radiative forcing compared to that of pure mineral dust. With a view to investigating further about the ubiquitous presence of polluted dust at higher altitudes beyond the altitude range of aircraft measurements, aerosol extinction coefficients $\left(\sigma_{\text {ext }}\right.$, in $\left.\mathrm{Mm}^{-1}\right)$ and PDRs from Cloud-Aerosol Lidar and Infrared Pathfinder Satellite Observations (CALIPSO) were examined.

\subsection{Vertical profiles of PDR}

The depolarisation ratios (defined as the ratio of the perpendicular to the parallel components of the range corrected aerosol backscatter in the Lidar profile) are useful indicators of the discrimination between spherical and non-spherical particles, liquid aerosol droplets and dust or cloud droplets (Winker et al. 2007). Higher depolarisation ratios $(\sim 0.3)$ indicate the presence of non-spherical dust particles, while lower PDR corresponds to spherical particles, which are more likely to be of anthropogenic origin, if in the accumulation regime. Categorisation of PDR for the accurate identification and quantification of dust has been reported to vary from 0.2 to 0.4 , whereas it is identified to be less than 0.05 for spherical particles (e.g., Freudenthaler et al. 2009; Tesche et al. 2009; Mamouri and Ansmann 2014 and references therein).

In the present study, we have examined vertical profiles of aerosol extinction coefficients and PDR (figure 7), averaged for all the profiles available within the $1^{\circ} \times 1^{\circ}$ grid around each of the experimental sites during the entire campaign period representing winter (18 November 2012 to 25 December 2012) and spring (25 April 2013 to 25 May 2013). We have used level-2 version 4.10 (V4) products (released in November 2016), which are the first wholly a new release of the CALIPSO Lidar level-2 (report on the geophysical parameters derived from level-1 data) data products since the initial release of the Version 3 (V3) series of products in May 2010. While level-2 data report quantities such as layer location (i.e., base, top, latitude and longitude), layer type (e.g., cloud or aerosol) and a number of derived optical parameters, including optical depths, V4 provides a substantial advance over V3 and earlier releases; known retrieval artifacts have been eliminated and numerous enhancements have been incorporated to increase the accuracy of the science data while simultaneously reducing uncertainties. In October 2018, the version 4.20 (V4) CALIOP data product was released, which was identical to the V4.10 data product with the addition of several HDF science data sets that provide information to the user for filtering out low-laser energy shots.

Based on the available profiles over a geographical grid during the period of flight operation in winter and spring, seasonal averaging of the CALIPSO profiles was made. The seasonal mean picture is presented due to the lack of simultaneous satellite overpasses to that of the aircraft measurement over a particular region. Thus, the profiles of $\sigma_{\text {ext }}$ and PDR are representative of the broad feature and are not concurrent. It is observed from figure 7 that the values of PDR over most of the Indian region were higher during spring compared to that during winter. Over the IGP (LKN) and HF (DDN), PDR shows a gradual increase in the altitude during spring with occurrences of very high values $(0.2-0.4$ at $\mathrm{LKN}$ and $>0.4$ at $\mathrm{DDN})$ above $3 \mathrm{~km}$. It is seen that, at LKN, the springtime values of PDR were higher than the values at winter prevailing up to an altitude of $2.5 \mathrm{~km}$. This is indicative of the contributions of coarse mode particles to the higher values of $\sigma_{\text {ext }}$ seen over LKN during spring above the well-mixed region; whereas lower values of $\mathrm{PDR} \sim 0.1$ in the mixing region is indicative of the dominant contribution of fine mode aerosols to the observed values of $\sigma_{\text {ext }}$. During winter, even though a higher value of $\mathrm{PDR}>0.3$ was noticeable at $\sim 3 \mathrm{~km}$ altitude over LKN, the simultaneous value of $\sigma_{\text {ext }}$ is not high. These observations thus support the presence of coarse particles in the NSD spectrum during spring, which is significant, resulting in the higher values of $\sigma_{\text {ext }}$ in spring.

Over the CI locations of HYD and NGP, vertical profiles of $\sigma_{\text {ext }}$ (a sharp reduction of $\sigma_{\text {ext }}$ in the wellmixed region followed by a near-steady pattern above $1 \mathrm{~km}$ ) in spring are similar to aerosol total number concentration $\left(N_{\mathrm{T}}\right)$ profiles seen in figure 2 . 


\section{(a)}

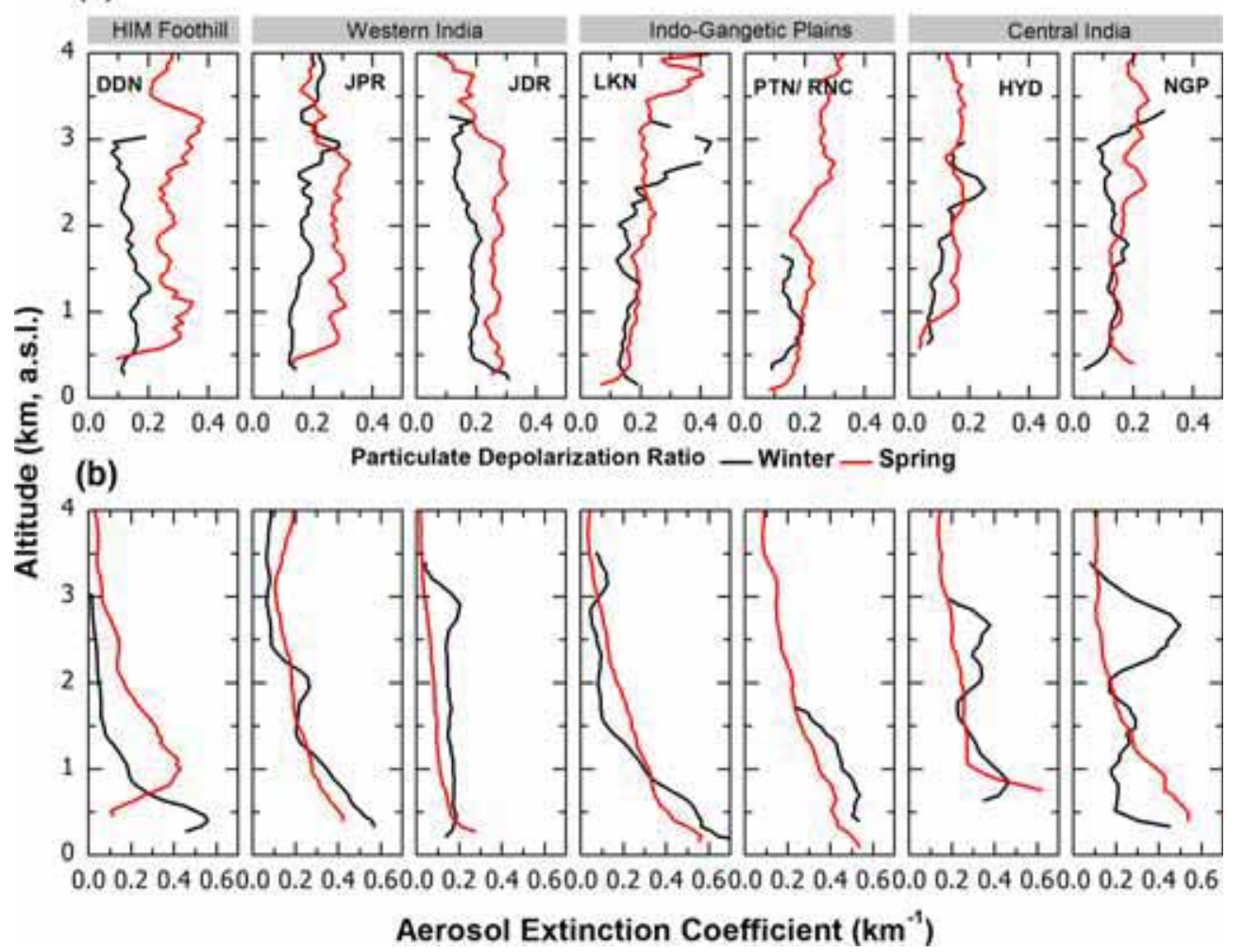

Figure 7. Vertical profiles of particulate depolarization ratio (PDR) and aerosol extinction coefficient (Data product - CALIPSO Level-2, Version 4.1 data, re-gridded to $1^{\circ} \times 1^{\circ}$ spatial resolution) over each of the study locations.

This is associated with a gradual increase in PDR from the surface to an altitude of $\sim 1.5 \mathrm{~km}$ at HYD and near-steady values at NGP. Over HYD, the corresponding PDR remains nearly steady $(\sim 0.15$ to 0.2 ) above the well-mixed region after increasing from a very low value (0.02) at the surface; while that over NGP increased beyond 0.2 at a higher altitude $(2-3 \mathrm{~km})$. An increase in PDR along with $N_{\mathrm{T}}$ at higher altitudes above the well-mixed region over both HYD and NGP during spring indicates the influence of dust aerosols at higher altitudes associated with the convective lifting due to solar heating. On the other hand, even though the values of PDR in winter significantly increase at a higher altitude over both HYD and NGP $(\sim 0.2$ at $2-3 \mathrm{~km}$ at HYD and $\sim 0.4$ at $3-4 \mathrm{~km}$ at NGP), the values of $\sigma_{\text {ext }}$ are not significantly high at the corresponding heights. Thus, even though the coarse mode aerosol fraction in the well-mixed region is higher in winter, the influence of dust aerosols is more significant in spring, to maintain observed consistent high values of $\sigma_{\text {ext }}$ associated with higher number concentrations. This is in agreement with the large $N_{\mathrm{T}}$ ratio shown in figure 3.

Over the WI locations JDR and JPR, steady $\mathrm{PDR}$ profiles (PDR 0.3) during spring indicate the presence of dust from the surface to about $3 \mathrm{~km}$. Whereas in winter, lower values of PDR $(<0.2)$ and the higher values of $\sigma_{\text {ext }}$ exist in the well-mixed region over both these locations, indicating a dominant contribution from fine mode particles to the aerosol extinction near the surface. While in JDR, polluted dust (PDR $\sim 0.2$ ) contributed significantly to the higher $\sigma_{\text {ext }}$ over the rest of the column. In contrast to this, PDR at JPR shows an increasing pattern with altitude suggesting the presence of dust transport at higher altitude levels, suggesting higher-CMF.

In general, peaks in the extinction coefficients and associated higher depolarisation ratios at higher altitudes suggest the presence of elevated dust. However, dust particles usually mix with local polluted particles (e.g., BC and OC) due to substantial anthropogenic emissions and/or uptake of secondary aerosol species in this region (e.g., water-soluble material) (Pósfai et al. 2013). Such internal and external mixing could change the chemical and morphological properties of dust, thus its radiative properties, which would be different from original dust. During biomass burning period, transported dust is commonly mixed with BC particles (e.g., Li and Shao 2009). As BC 
particles are always aggregates composed of ten to hundreds of tiny and nearly spherical monomers, dust particles can provide reaction sites for heterogeneous chemical reactions and particle coagulations. Li and Shao (2009) have reported examples of dust particles coated in more than $90 \%$ of haze samples. Thus the polluted dust is more spherical in nature leading to lower values of depolarisation ratios. The presence of polluted dust as evident from CALIPSO PDR over the winter atmosphere over India needs to be properly modelled for remote sensing and radiation balance applications.

With a view to understanding the distinct aerosol types prevailing during the flight operations, we have further examined the CALIOP vertical feature mask (VFM) and aerosol types over the selected Indian regions. VFM indicates different atmospheric features detected by selective, iterated boundary location algorithm that includes: (i) clean air, (ii) cloud, (iii) tropospheric aerosols, (iv) stratospheric aerosol, (v) surface, (vi) sub-surface and (vii) totally attenuated condition during the satellite overpasses. Similarly, based on the back-scattered intensity and depolarisation ratio observations, the CALIOP Lidar ratio selection algorithm classifies the tropospheric aerosols into seven subtypes: (i) marine, (ii) dust, (iii) polluted continental/ smoke, (iv) clean continental, (v) polluted dust (dust mixed with anthropogenic aerosols), (vi) elevated smoke and (vii) dusty marine.

Figure 8 shows the cross-sectional views of CALIOP VFM (level-2 version-4.1) along the track of the satellite overpasses over the Indian region for a few representative days of winter and spring during the period of aircraft experiment. The orbits tracks of CALIPSO are shown in the inset. The figure clearly shows the confinement of tropospheric aerosols below $3 \mathrm{~km}$ during winter, which extends up to an altitude as high as $5 \mathrm{~km}$ during spring. With a view to examining the contributions of different aerosol types to the altitudinal and spatiotemporal variations of aerosols, the frequency of occurrence of each of the aerosol types at different vertical regimes is estimated. For this, we have considered all the CALIOP profiles available within the $1^{\circ} \times 1^{\circ}$ grid around each of the experimental site during the entire campaign period (18 November 2012 to 25 December 2012 for winter and 25 April 2013 to 25 May 2013 for May). The frequency distribution of four dominant aerosol types is shown in figure 9, which clearly demonstrates the vertical inhomogeneity of the occurrences of distinct types of aerosols (e.g., dust, polluted dust, elevated smoke and polluted continental/smoke) over different geographic regions and seasons. The signature of dust loading at higher altitudes during spring is a consistent feature over most of the Indian locations. Over the IGP, higher dust loading in spring is accompanied largely by the occurrences of polluted dust in the lower-FT regions. On the other hand, the dominated aerosol types over the IGP during winter are polluted continental and smoke aerosols. Similarly, higher occurrence of the elevated smoke over WI during winter is significant, the scenario which also changes to the dominance of dust and polluted dust during spring. Higher occurrence of the presence of elevated smoke and polluted dust is also seen over the HF during winter, while the dominance of dust loading during spring is very significant over this region.

\subsection{Moderate resolution imaging spectroradiometer (MODIS) fire counts}

One of the major processes that can pollute dust at higher altitudes (as seen during winter) is by emissions, either from natural (biomass burning) or anthropogenic (vehicular or industrial) sources. Over the urban/continental locations of India, emissions from vehicular combustions, brick kilns and coal burning assume dominant shares (Ghosh et al. 2014) but they need focused observations with emission estimates and modelling efforts to quantify. But large-scale biomass burning contributions can be delineated from space-borne observations. In this regard, to examine emissions from biomass burning sources, MODIS (collection-5, version-6) cloud and overpass corrected fire pixels counts were examined.

The MODIS instrument on board the Terra and Aqua EOS satellites acquires data by continuously providing global coverage every 1-2 days. Terra and Aqua satellites pass over the equator at $\sim$ 10:30 am to 1:30 pm every day. There are at least 2 daily MODIS fire observations for almost every area on the equator, with the number of overpasses increasing (due to overlapping orbits) closer to the poles. The fire pixels indicate the geographic position and the magnitude of the fire events, which are identified based on a contextual algorithm that exploits the strong emission of midinfrared radiation from fires. This algorithm examines each pixel of the MODIS swath, and ultimately assigns to each one of the following classes: missing data, cloud, water, non-fire, fire or 

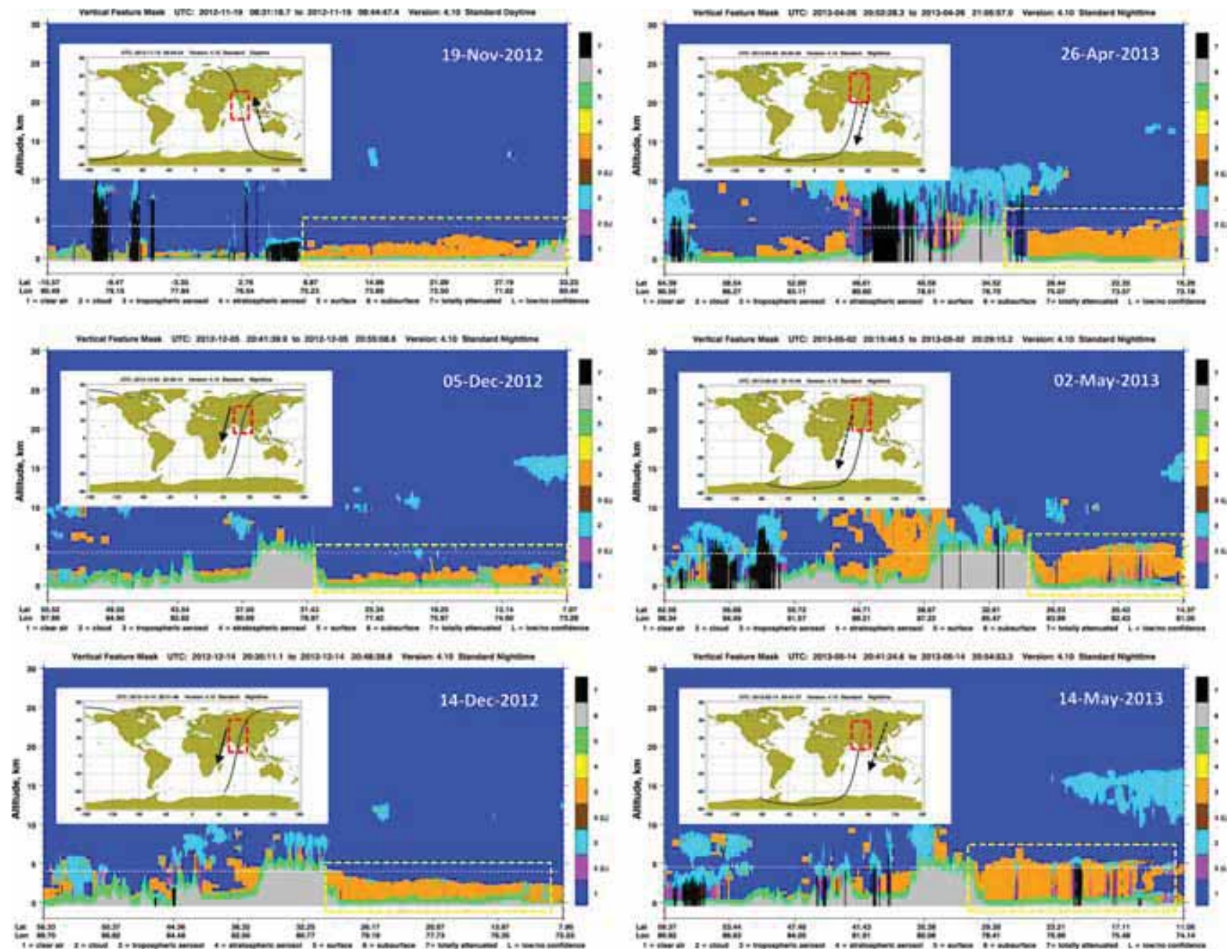

Figure 8. Vertical feature mask along the satellite track during a few representative days of winter 2012 and spring 2013 . The satellite tracks are shown in the inset and the red rectangular boxes in the satellite tracks show the section of satellite passes for which the profiles of VFM are shown. The yellow rectangular boxes denote spread of VFM across the Indian region along the satellite track.

unknown (Giglio et al. 2003). In some cases, MODIS cannot detect certain fire if the fire starts and ends between satellite overpasses. Occasionally, the too small or too cool fire cannot be detected.

In the present study, the spatio-temporal distribution of the fire pixel counts is examined for the months of October, November and December 2012 and March, April and May 2013. Even though the figure is representative of a monthly picture, it is indicative of the seasonal transformation of the fire activities from winter to spring showing distinct regional distributions.

As shown in figure 10, the considerable presence of biomass burning over northern India, towards the south-west of DDN is clearly noticeable in the month of October and November 2012. The observed higher values of $N_{\mathrm{T}}$ in the elevated regions of DDN in winter are thus supported by these additional local/regional source impacts, coupled with wintertime temperature inversions taking place due to the unique topography of the region. The high hills and mountains located in the north and eastern side of DDN play a key role in creating temperature inversion as it can cause cold air to flow from mountain peaks down into valleys. This cold air then pushed under warmer air rising from the valley, creating the inversion. Thus regionally emitted smoke or polluted dust, which is injected to the higher altitude during the post monsoon (October-November) season, may reside over a longer period spanning until winter, leading to the higher aerosol number concentrations at higher altitudes in winter. While other regions did not seem to have any close-by biomass burning emission sources, the transport component cannot be neglected. 

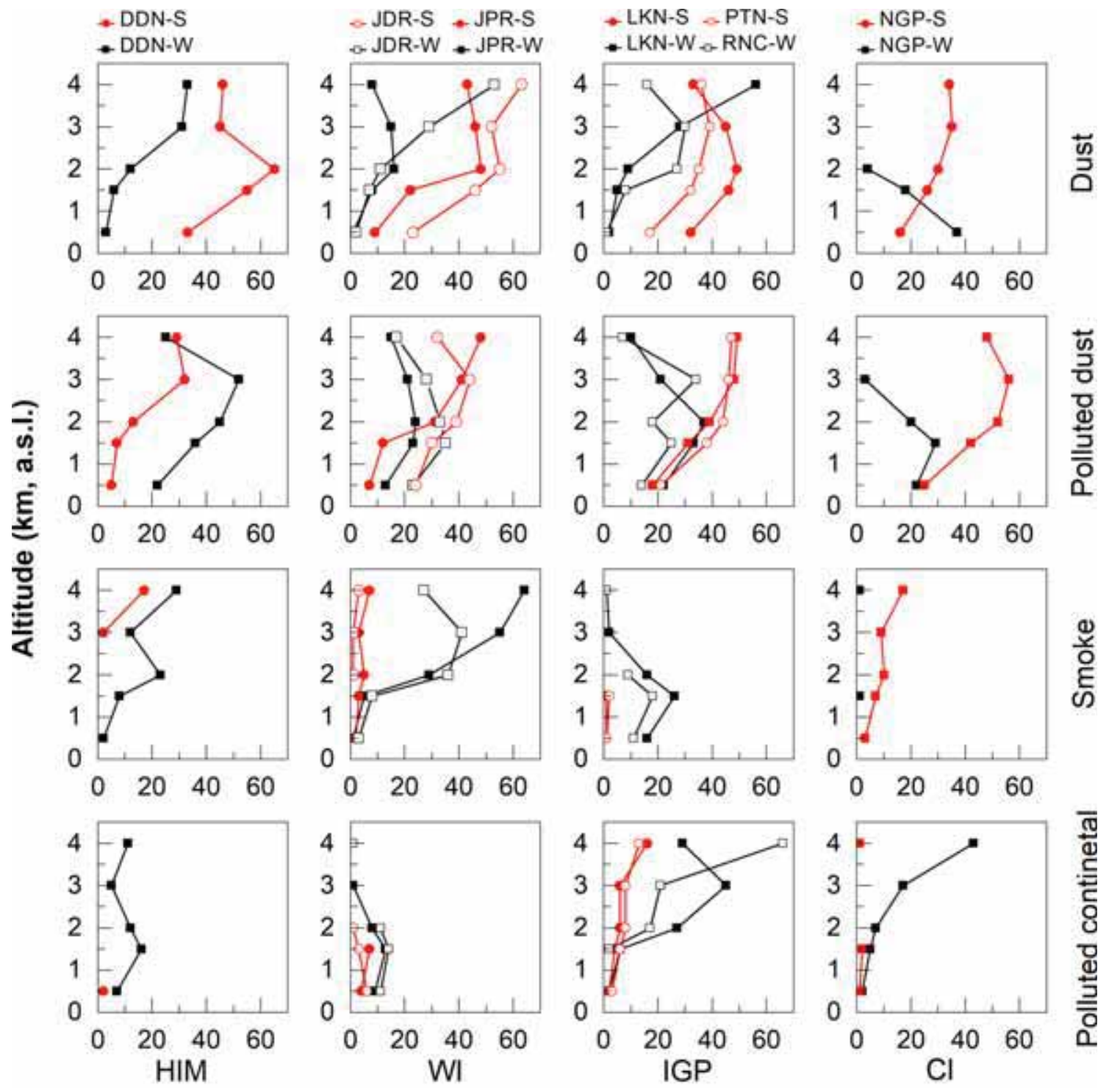

Frequency of occurrences (\%)

Figure 9. Vertical distribution of the frequency of occurrences of dominant aerosol types (Dust, Polluted dust, Smoke and Polluted continental) over each of the study locations, obtained from all the CALIOP profiles available within $1^{\circ} \times 1^{\circ}$ grid around each of the experimental site during the entire campaign period (18 Nov 2012 to 25 Dec 2012 for winter and 25 Apr 2013 to 25 May 2013 for spring).

\subsection{Role of transport}

Analysis of 5-day isentropic back trajectory (using HYSPLIT FNL data sets) was carried out for the respective days of the areal sorties at each site to understand the advection pathways favouring a long-range transport (figure 11). The receptor altitude at $\sim 1500 \mathrm{~m}$ above ground level (AGL) is considered typical to understand the major pathways. It is seen from figure 11 that, in most of the cases except HYD, air masses during spring originated at the far African desert regions and traversed through the arid/desert regions of northwestern India, before arriving at the receptor sites.
In the case of HYD, the origin of air masses during spring was confined to the northern part of India, except in a single day, during which air masses originated in the marine region of the Bay of Bengal. Over the north Indian IGP location of LKN, the air masses in spring originated in the far African desert regions; while during winter, most of the air masses originated in the Indian desert regions. Similarly, in the case of the HF region in winter, trajectories ending at DDN had significant overpass time over the desert and continental regions of WI. Over the WI locations of JDR and JPR, air mass pathways are similar to those arriving at the IGP site LKN. The above 

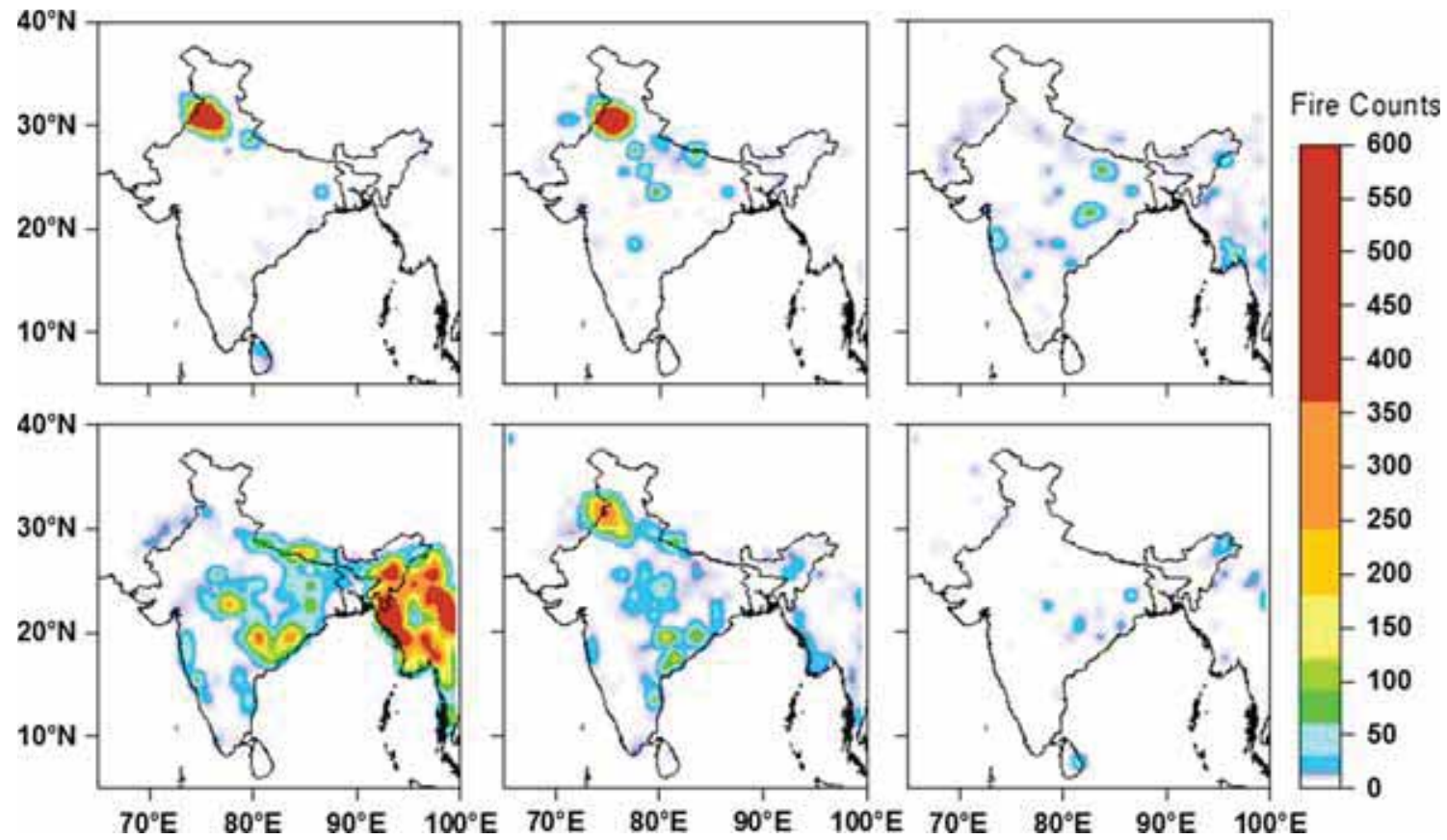

Figure 10. MODIS fire count map over the Indian region during October, November and December, 2012 (top panel, L-R) and April, May and June, 2013 (bottom panel, L-R), shows the biomass burn areas to the west of DDN in the northern part of India during October-November and in May.

observation clearly supports the significant role of dust transport to the northern part of India during the spring season.

\subsection{Aerosol optical properties}

In figure 12, we present the mean values of aerosol absorption coefficients ' $\sigma_{\mathrm{abs}}$ ' for each of the regions, obtained from the concurrent measurements, for the well-mixed region and the lower FT. In the bottom panel, the corresponding absorption aerosol optical depth 'AAOD' (estimated by integrating vertical profiles of $\sigma_{\text {abs }}$ from the surface to ceiling altitude $\sim 3.5 \mathrm{~km}$ of aircraft measurement) is shown.

As seen from the top panel of figure 12, in the FT, the magnitude of aerosol absorption (as indicated by the higher values of $\sigma_{\text {abs }}$ ) during spring is significantly higher over the IGP than the values at WI, HF and CI locations. Seasonally, the spring time values of $\sigma_{\mathrm{abs}}$ in the FT region of IGP are nearly double the values during winter. The lowestFT values of aerosol absorption during spring is seen over the WI region, as the region is comparatively less influenced by the industrial and biomass burning activities in comparison with the other parts of the country. This is also in line with the values of CALIPSO extinction coefficients (as shown in figure 7), as well as, the higher values of
PDR and coarse-mode aerosol concentrations. However, over the $\mathrm{HF}$ and $\mathrm{CI}$ regions, the FT values of $\sigma_{\text {abs }}$ are higher even in winter. This observation is also in line with the vertical profiles of the frequency distributions of elevated smoke, showing significant presence during the winter season. In the well-mixed region (ML: middle panel of figure 12), the nature of aerosol absorption changes and has dominance of $\sigma_{\text {abs }}$ over the IGP in winter.

In the case of AAOD, the $\mathrm{HF}$ region shows the highest AAOD during spring, whereas other regions showed higher AAOD during winter. Over the IGP, the difference between winter and spring was minimal indicating the influence of large-scale anthropogenic activities during both winter and spring, where the overall columnar contribution from the intense surface contribution during winter is replaced with strong contribution from FT during spring. A similar feature is also reflected in the vertical profiles of the frequency distributions of dust, polluted dust and elevated smoke occurring over the IGP, which leads to the enhancement of $\sigma_{\text {abs }}$ during spring in the FT region of IGP with a subsequent decrease in the values of $\sigma_{\text {abs }}$ in the ML region.

Using the vertical profiles of scattering and absorption coefficient, we have estimated the mean values of aerosol SSA (or $\omega=$ ratio of scattering coefficients to extinction coefficients) for the FT 

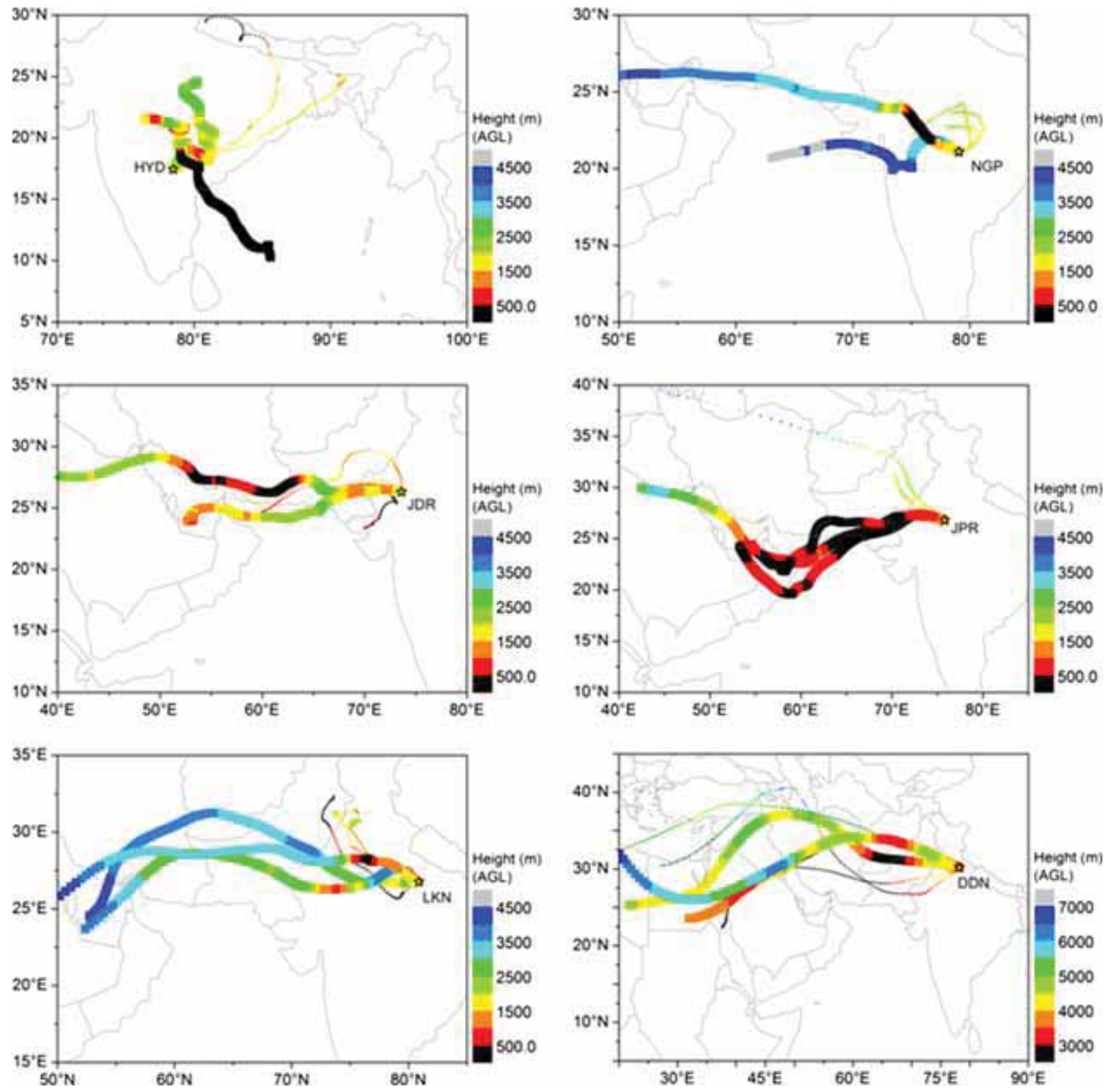

Figure 11. HYSPLIT airmass back-trajectory analysis ending at lower free-tropospheric regions (1500 m AGL) over the measurement locations (other than DDN). Over DDN, the trajectories are calculated with respect to receptor height of $3100 \mathrm{~m}$ AGL. The solid square (bigger) symbols are used to represent spring, while star (smaller) symbols represent winter. The colors represent the height of the air parcels above ground level (AGL).

regions (i.e., considering values above $2 \mathrm{~km}$ altitude) and this is shown in figure 13 for each of the FT regions above the observational sites. Generally varying between 0.7 and 1 in the atmosphere, SSA decides whether aerosols cool or warm the top of the atmosphere. The mean values of SSA at $520 \mathrm{~nm}$ in the FT regions clearly indicate the relative dominance of absorbing aerosols in spring, which is most significant over the IGP, leading to comparable values of AAOD during winter and spring.

The larger dispersion of the absorbing aerosols to higher altitudes during spring, as indicated by the difference in the values of $\sigma_{\text {abs }}$ has more radiative implications, even though the AAOD values during both winter and spring were comparable. Nair et al. (2016) have reported that the advection of west Asian dust at lower FT contributes to high-AAOD values during the spring season, leading to vertical heterogeneity in the distribution of coarse-mode aerosols and the presence of elevated layers of absorbing aerosols during spring over the northern parts of India. A decrease in BC mass concentration at the surface from winter to spring is also indicative of vertical redistribution and accumulation in the lower FT (Nair et al. 2016). This would contribute significantly to the diabatic heating in 

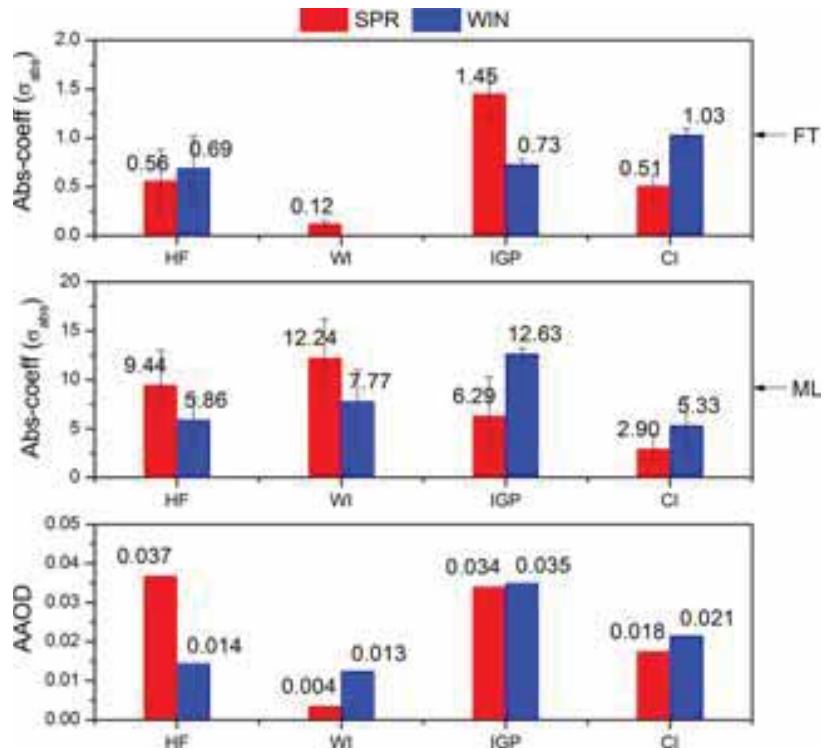

Figure 12. Regional mean values of aerosol absorption coefficients at $781 \mathrm{~nm}$ in the well-mixed layer (ML) and freetropospheric (FT) regions of HF, WI, IGP and CI. The values of absorption aerosol optical depths (AAOD) are also shown in the bottom panel.

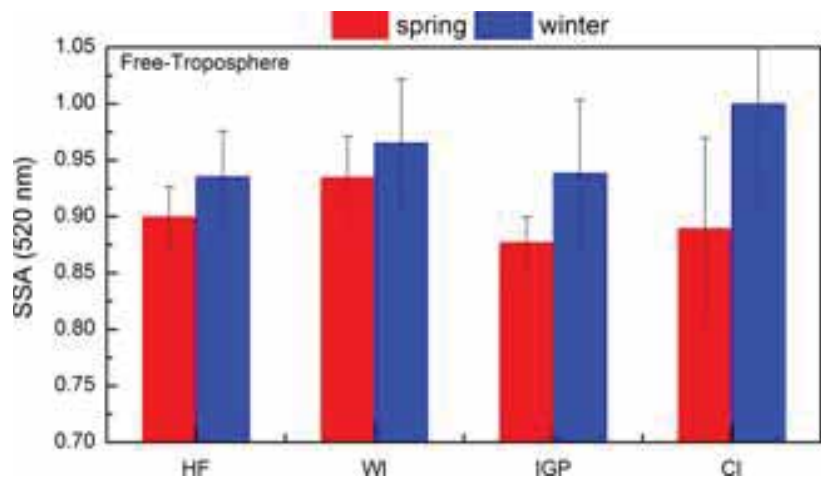

Figure 13. Regional mean values of SSA at $520 \mathrm{~nm}$ over the distinct lower-FT regions (above $2 \mathrm{~km}$ ) of the HF, WI, IGP and CI during spring and winter.

the lower-FT region (Babu et al. 2016). During the winter season, the relative dominance of absorbing aerosols is mostly confined within the boundary layer (as indicated by the lower SSA), their contribution to the total extinction above the boundary layer (higher SSA) does not have significant implications on the radiative forcing (Babu et al. 2016).

From the measurement of aerosol optical properties during the same experiment, Nair et al. (2016) have reported that higher dust absorption during spring over IGP leads to $+34.0 \mathrm{~W} \mathrm{~m}^{-2}$ atmospheric absorption as against the value of $+24.9 \mathrm{~W} \mathrm{~m}^{-2}$ during winter. Due to the presence of dust and elevated smoke over the
IGP in spring, the region experiences $\sim 8 \mathrm{~W} \mathrm{~m}^{-2}$ more atmospheric warming compared to CI and $\sim 14 \mathrm{~W} \mathrm{~m}^{-2}$ than WI. On the other hand, atmospheric forcing during winter and spring are $+14.7 \mathrm{~W} \mathrm{~m}^{-2}$ and $+19.8 \mathrm{~W} \mathrm{~m}^{-2}$, respectively, over the western part of India. The observation in the present study is also consistent with the inferences drawn by Nair et al. (2016) that spring-time dust transport over the region compensates the partial decrease in columnar BC loading. Quantification of radiative implications due to such distinct aerosol characteristics needs further detailed studies.

\section{Summary and conclusions}

The present study examined the vertical distribution of aerosol concentration and NSD and its seasonality over distinct locations of the Indian mainland using campaign-mode in-situ measurements aboard an instrumented aircraft.

The main findings are as follows:

1. Vertical distribution of aerosols during spring is homogeneous over most of the Indian regions due to enhanced thermal convective mixing, while a shallow-boundary layer and a local source in winter enhance the total number concentrations of aerosols near the surface. Near surface concentrations of aerosols in winter were the highest over LKN in the IGP, indicating the strong influence of local anthropogenic sources during shallow-boundary layer conditions in winter.

2. The springtime enhancement of $N_{\mathrm{T}}$ at a higher altitude (above $2 \mathrm{~km}$ ) was more significant over the CI and WI locations, mostly contributed by fine-mode aerosols, as indicated by the lower values of the CMF. During spring, prevailing higher temperatures over the CI and WI locations lead to strong turbulent mixing and vertical dispersion of aerosols to higher altitudes.

3. Over the HF location DDN, aerosol concentrations were, however, higher in winter in the entire altitude range. The higher aerosol concentration at DDN during winter is influenced by the advection from the densely populated regions. Trajectories ending at DDN during winter also traversed over the desert and continental regions of the WI, which contributed to the transport of a large number of coarse particles, even with sizes $>2 \mu \mathrm{m}$. 
4. Over the IGP, coarse-mode aerosols were found to ventilate strongly to the higher altitudes during spring, in addition to horizontal advection from the west, enhancing the total number of particle concentrations (in comparison with winter) in the lower FT $(>2 \mathrm{~km})$.

5. Aerosol NSDs in lower-altitude regions (up to around $1000 \mathrm{~m}$ AGL) showed, in general, higher concentrations in winter for the entire size range $(0.5-20 \mu \mathrm{m})$ over all the measurement locations. However, at higher altitudes $(>2 \mathrm{~km})$, there were notable changes in the distribution patterns in spring with higher-coarse mode concentrations. Thus, in the higher altitude regions, even though the enhancement in $N_{\mathrm{T}}$ in spring was mainly due to the contributions by fine mode aerosols, the presence of coarse-mode particles $(>2 \mu \mathrm{m})$ is more significant over the IGP.

6. Examination of the CALIPSO extinction coefcients, PDR, VFM and aerosol types, along with MODIS fire counts over the study regions indicated the presence of dust and polluted dust (semi-external mixtures of dust with BC or OC) at higher altitudes over the IGP, CI and northwestern India. The presence of dust in the IGP contributes significantly to the higher values of extinction coefficients.

7. Concurrent and collocated measurements of aerosol scattering and absorption properties onboard the aircraft also corroborated to the enhancement in aerosol absorption coefficients in the FT regions of IGP along with a decrease in the values of aerosol single scattering albedo. This confirms that the elevated layers of coarse mode aerosols seen during spring over the IGP are absorbing in nature.

\section{Acknowledgements}

This study was carried out as part of the Regional Aerosol Warming Experiment (RAWEX) under the Aerosols and Radiative Forcing over India (ARFI) project of ISRO-Geosphere Biosphere Programme (ISRO-GBP). We acknowledge the National Remote Sensing Centre (NRSC), Hyderabad for the support with the aircraft operation and measurements. S. Suresh Babu acknowledges the Department of Science Technology for the Swarna Jayanti Fellowship. We also acknowledge NOAA Air Resources Laboratory for the provision of the HYSPLIT transport and dispersion model and READY website (http://www.arl.noaa.gov/ ready.html) used in this publication. The CALIPSO data were obtained from the NASA Langley Research Centre and Atmospheric Sciences Data Centre.

\section{References}

Anderson T L and Ogren J A 1998 Determining aerosol radiative properties using the TSI 3563 integrating nephelometer; Aerosol Sci. Technol. 29 57-69.

Arnott W P, Hamasha K, Moosmuller H, Sheridan P J and Ogren J A 2005 Towards aerosol light-absorption measurements with a 7-wavelength aethalometer: Evaluation with a photoacoustic instrument and 3-wavelength nephelometer; Aerosol Sci. Technol. 39(1) 17-29.

Babu S S, Moorthy K K and Satheesh S K 2006 Temporal heterogeneity in aerosol characteristics at a tropical coastal station and the resulting radiative impacts; In: Remote Sensing of the Atmosphere and Clouds Proceedings of SPIE vol. 6408 , pp. 640813 .

Babu S S et al. 2013 Trends in aerosol optical depth over Indian region: Potential causes and impact indicators; $J$. Geophys. Res. Atmos. 118, https://doi.org/10.1002/ 2013jd020507.

Babu S S, Nair V S, Gogoi M M and Moorthy K K 2016 Seasonal variation of vertical distribution of aerosol single scattering albedo over Indian sub-continent: RAWEX aircraft observations; Atmos. Environ. 125 312-323.

Barman S C et al. 2017 Assessment of ambient air quality in Lucknow city, CSIR-Indian Institute of Toxicology Research, Lucknow, 2017.

Beegum N, Moorthy K K, Babu S S, Satheesh S K, Vinoj V, Badarinath K V S, Safai P D, Devara P C S, Singh S, Vinod, Dumka U C and Pant P 2009 Spatial distribution of aerosol black carbon over India during pre-monsoon season; Atmos. Environ. 43 1071-1078.

Census 2011 Primary census abstracts, Registrar general of India, Ministry of Home Affairs, Government of India, http://www.censusindia.gov.in/pca/Searchdata.aspx.

Dubovik O and Li Z et al. 2018 Polarimetric remote sensing of atmospheric aerosols: Instruments, methodologies, results, and perspectives; J. Quant. Spectrosc. Radiat. Transfer 224 474-511.

Freudenthaler V, Esselborn M, Wiegner M, Heese B, Tesche M, Ansmann A, Müller D, Althausen D, Wirth M, Fix A, Ehret G, Knippertz P, Toledano C, Gasteiger J, Garhammer M and Seefeldner M 2009 Depolarization ratio profiling at several wavelengths in pure Saharan dust during SAMUM 2006; Tellus B 6116579.

Gautam R, Hsu N C and Lau K M 2010 Pre-monsoon aerosol characterization and radiative effects over the IndoGangetic Plains: Implications for regional climate warming; J. Geophys. Res. 115(D17) 1984-2012.

Gautam R, Hsu N C, Tsay S C, Lau K M, Holben B, Bell S, Smirnov A, Li C, Hansell R, Ji Q, Payra S, Aryal D, Kayastha R and Kim K M 2011 Accumulation of aerosols over the Indo-Gangetic plains and southern slopes of the Himalayas: Distribution, properties and radiative effects 
during the 2009 pre-monsoon season; Atmos. Chem. Phys. 11(24) 12841-12863.

Ghosh S, Gupta T, Rastogi N, Gaur A, Misra A, Tripathi S N, Paul D, Tare V, Prakash O, Bhattu D, Dwivedi A K, Kaul D S, Dalai R and Mishra S K 2014 Chemical characterization of summertime dust events at kanpur: Insight into the sources and level of mixing with anthropogenic emissions; Aerosol Air Qual. Res. 14 879-891.

Giglio L, Descloitres J, Justice C O and Kaufman Y 2003 An enhanced contextual fire detection algorithm for MODIS; Remote Sens. Environ. 87 273-282. https://doi.org/10. 1016/s0034-4257(03)00184-6.

Gogoi M M, Moorthy K K, Babu S S and Bhuyan P K 2009 Climatology of columnar aerosol properties and the influence of synoptic conditions: First-time results from the northeastern region of India; J. Geophys. Res. 114(D8) 1984-2012.

Gogoi M M, Pathak N, Moorthy K K, Bhuyan P K, Babu S S, Bhuyan K and Kalita G 2011 Multi-year investigations of near surface and columnar aerosols over Dibrugarh, northeastern location of India: Heterogeneity in source impacts; Atmos. Env. 45 1714-1724.

Gogoi M M, Babu S S, Moorthy K K, Manoj M R and Chaubey J P 2013 Absorption characteristics of aerosols over the northwestern region of India: Distinct seasonal signatures of biomass burning aerosols and mineral dust; Atmos. Environ. 73 92-102.

Gogoi M M, Moorthy K K, Kompalli S K, Chaubey J P, Babu S S, Manoj M R, Nair V S and Prabhu T P 2014 Physical and optical properties of aerosols in a free tropospheric environment: Results from long-term observations over western trans-Himalayas; Atmos. Environ. 84 262-274.

Huebert B J, Howell S G, Covert D S, Bertram T, Clarke A D, Anderson J R, Lafleur B G, Seebaugh W R, Wilson J C, Gesler D, Blomquist B W and Fox J 2004 PELTI: Measuring the passing efficiency of an airborne low turbulence aerosol inlet; Aerosol Sci. Technol. 38 803-826.

Junge CE 1963 Air chemistry and radioactivity; Academic Press, New York, pp. Xii, 382.

Kompalli S K, Babu S S, Moorthy K K, Manoj M R, Kiran Kumar N V P, Hareef Baba Shaeb K and Joshi A K 2014 Aerosol black carbon characteristics over central India: Temporal variation and its dependence on mixed layer height; Atmos. Res. 147-148 27-37.

Lau K M, Kim M K and Kim K M 2006 Asian summer monsoon anomalies induced by aerosol direct forcing: The role of the Tibetan Plateau; Clim. Dyn. 26(78) 855-864.

Lawrence M G and Lelieveld J 2010 Atmospheric pollutant outflow from southern Asia: A review; Atmos. Chem. Phys. 10(22) 11017-11096.

Lelieveld J, Berresheim H, Borrmann S, Crutzen P J, Dentener F J, Fischer H, Feichter J, Flatau P J, Heland J, Holzinger R, Korrmann R, Lawrence M G, Levin Z, Markowicz K M, Mihalopoulos N, Minikin A, Ramanathan V, De Reus M, Roelofs G J, Scheeren H A, Sciare J, Schlager H, Schultz M, Siegmund P, Steil B, Stephanou EG, Stier P, Traub M, Warneke C, Williams J and Ziereis H 2002 Global air pollution crossroads over the Mediterranean; Science 298(5594) 794-799.

Li W J and Shao L Y 2009 Transmission electron microscopy study of aerosol particles from the brown hazes in northern China; J. Geophys. Res. 114 D09302.
Mamouri R E and Ansmann A 2014 Fine and coarse dust separation with polarization lidar; Atmos. Meas. Tech. 7 3717-3735.

Mc Naughton C S, Clarke A D, Howell S G, Pinkerton M, Anderson B, Thornhill L, Hudgins C, Winstead E, Dibb J E, Scheuer E and Maring H 2007 Results from the DC-8 inlet characterization experiment DICE): Airborne versus surface sampling of mineral dust and sea salt aerosols; Aerosol Sci. Technol. 41 136-159.

Mishra A K and Shibata T 2012a Climatological aspects of seasonal variation of aerosol vertical distribution over central Indo-Gangetic belt (IGB) inferred by the spaceborne lidar CALIOP; Atmos. Environ. 46 365-375.

Mishra A K and Shibata T 2012b Synergistic analyses of optical and microphysical properties of agricultural crop residue burning aerosols over the Indo-Gangetic Basin (IGB); Atmos. Environ. 57 205-218.

Mönkkönen P, Koponen I, Lehtinen K, Hämeri K, Uma and Kulmala M 2005 Measurements in a highly polluted Asian mega city: Observations of aerosol number size distributions, modal parameters and nucleation events; Atmos. Chem. Phys. 5 57-66.

Moorthy K K and Satheesh S K 2000 Characteristics of aerosols over a remote island, Minicoy in the Arabian Sea: Optical properties and retrieved size characteristics; Quart. J. Roy. Meteorol. Soc. 126 81-109.

Moorthy K K, Babu S S and Satheesh S K 2007 Temporal heterogeneity in aerosol characteristics and the resulting radiative impact at a tropical coastal station - Part 1: Microphysical and optical properties; Ann. Geophys. 25 2293-2308.

Moorthy K K, Babu S S, Manoj M R and Satheesh S K 2013 Buildup of aerosols over the Indian region; Geophys. Res. Lett. 40(5) 1011-1014.

Nair V S, Moorthy K K, Alappattu D P, Kunhikrishnan P K, George S, Nair P R, Babu S S, Abish B, Satheesh S K, Tripathi S N, Niranjan K, Madhavan B L, Srikant V, Dutt C B S, Badarinath K V S and Reddy R R 2007 Wintertime aerosol characteristics over the Indo-Gangetic Plain (IGP): Impacts of local boundary layer processes and long-range transport; J. Geophys. Res. 112(D13) D13205.

Nair V S, Babu S S, Gogoi M M and Moorthy K K 2016 Largescale enhancement in aerosol absorption in the lower free troposphere over continental India during pre-monsoon; Geophys. Res. Lett. 43 11453-11461, https://doi.org/10. 1002/2016gl070669.

Pillai P S and Moorthy K K 2001 Aerosol mass-size distributions at a tropical coastal environment: Response to mesoscale and synoptic processes; Atmos. Environ. 35 4099-4112.

Pósfai M, Axisa D, Tompa É, Freney E, Bruintjes R and Buseck P R 2013 Interactions of mineral dust with pollution and clouds: An individual-particle TEM study of atmospheric aerosol from Saudi Arabia; Atmos. Res. 122 347-361.

Prospero J M, Charlson R J, Mohnen V, Jaenicke R, Delany A C, Meyers J, Zoller W and Rahn K 1983 The atmospheric aerosol system: An overview; Rev. Geophys. Space Phys. 21 1607-1629.

Reddy R R, Gopal K R, Narasimhulu K, Reddy L S S and Kumar K R 2007 Aerosol Size Distribution Variation in Anantapur $\left(14.62^{\circ} \mathrm{N}, 77.65^{\circ} \mathrm{E}\right)$ Semi Arid Zone and its 
Impact on Aerosol Effective Radius; Aerosol and Air Quality Res. 7(4) 550-562.

Satheesh S K, Ramanathan V, Holben B N, Moorthy K K, Loeb N G, Maring H, Prospero J M and Savoie D 2002 Chemical, microphysical, and radiative effects of Indian Ocean aerosols; J. Geophys. Res. 107(D23) 4725.

Satheesh S K, Moorthy K K, Babu S S, Vinoj V and Dutt C B S 2008 Climate implications of large warming by elevated aerosol over India; Geophys. Res. Lett. 35(19) L19809.

Sullivan R C and Prather K A 2007 Investigations of the diurnal cycle and mixing state of oxalic acid in individual particles in Asian aerosol outflow; Environ. Sci. Technol. 41(23) 8062-8069.

Tesche M, Ansmann A, Müller D, Althausen D, Engelmann R, Freudenthaler V and Groß S 2009 Vertically resolved separation of dust and smoke over Cape Verde using multiwavelength Raman and polarization lidars during Saharan Mineral Dust Experiment 2008; J. Geophys. Res. 114 D13202.

Vanderpool R W and Rubow K L 1988 Generation of large, solid, monodisperse calibration aerosols; Aerosol Sci. Tech. 9 65-69.

Corresponding editor: Amit Kumar Patra
Verma S, Boucher O, Shekar Reddy M, Upadhyaya H C, Le Van P, Binkowski F S and Sharma O P 2012 Tropospheric distribution of sulphate aerosols mass and number concentration during INDOEX-IFP and its transport over the Indian Ocean: A GCM study; Atmos. Chem. Phys. 12(14) 6185-6196.

Volckens J and Peters T M 2005 Counting and particle transmission efficiency of the aerodynamic particle sizer; $J$. Aerosol Sci. 36(12) 1400-1408.

Winker D M, Hunt W H and McGill M J 2007 Initial performance assessment of CALIOP; Geophys. Res. Lett. 34(19) L19803.

Yang E S, Gupta P and Christopher S A 2009a Net radiative effect of dust aerosols from satellite measurements over Sahara; Geophys. Res. Lett. 36(18) L18812.

Yang M, Howell S G, Zhuang J and Huebert B J 2009b Attribution of aerosol light absorption to black carbon, brown carbon, and dust in China-interpretations of atmospheric measurements during EAST-AIRE; Atmos. Chem. Phys. 9(6) 2035-2050. 